\title{
Patient blood management during cardiac surgery: Do we have enough evidence for clinical practice?
}

\author{
Marco Ranucci, MD, ${ }^{a}$ Solomon Aronson, MD, ${ }^{\mathrm{b}}$ Wulf Dietrich, MD, PhD, ${ }^{\mathrm{c}}$ Cornelius M. Dyke, MD, ${ }^{\mathrm{d}}$ \\ Axel Hofmann, ME, ${ }^{\text {e,f }}$ Keyvan Karkouti, MD, ${ }^{\mathrm{g}}$ Marcel Levi, MD, PhD, ${ }^{\text {h }}$ Gavin J. Murphy, MD, FRCS, ${ }^{\mathrm{i}}$ \\ Frank W. Sellke, MD ${ }^{\mathrm{j}}$ Linda Shore-Lesserson, $\mathrm{MD},{ }^{\mathrm{k}}$ and Christian von Heymann, $\mathrm{MD},{ }^{1}$ endorsed by the \\ European Association of Cardiothoracic Anaesthesiologists (EACTA)
}

Transfusion of allogeneic blood products during and after cardiac operations is common. When the degree of anemia and the consequent decrease in oxygen delivery lead to organ ischemia, there is little doubt that red blood cell (RBC) transfusion is necessary. In addition, treatment with fresh-frozen plasma and platelets may be necessary to support coagulation. Treatment with blood products may also aim to prevent hemodynamic instability from excessive postoperative blood loss. A large body of evidence, however, indicates that transfusion of blood products per se may be associated with increased morbidity and mortality after cardiac operations. ${ }^{1-4}$ It is therefore important to assess the real versus perceived need for the transfusion of allogeneic RBCs and other blood

\footnotetext{
From the Department of Cardiothoracic-vascular Anesthesia and Intensive Care, ${ }^{a}$ IRCCS Policlinico S. Donato, Milan, Italy; the Department of Anesthesiology, ${ }^{b}$ Duke University Medical Center, Durham, NC; the Working Group on Perioperative Hemostasis, ${ }^{\mathrm{c}}$ Department of Anaesthesia, Ludwig Maximilian University Muenchen, Munich, Germany; SouthEast Texas Cardiovascular Surgery Associates, PA, ${ }^{\mathrm{d}}$ Houston, Tex; Centre for Population Health Research, ${ }^{\mathrm{e}}$ Curtin Health Innovation Research Institute (CHIRI), Curtin University, Perth, Western Australia; the Medical Society for Blood Management, ${ }^{\mathrm{f}}$ Laxenburg, Austria; the Department of Anesthesia, ${ }^{\mathrm{g}}$ Toronto General Hospital, University Health Network, University of Toronto, Toronto, Ontario, Canada; the Department of Vascular Medicine and Internal Medicine, ${ }^{\text {h }}$ Academic Medical Center, University of Amsterdam, Amsterdam, The Netherlands; the Bristol Heart Institute, ${ }^{i}$ University of Bristol, Bristol Royal Infirmary, Bristol, United Kingdom; the Division of Cardiothoracic Surgery, ${ }^{j}$ Alpert Medical School of Brown University, Rhode Island Hospital, Providence, RI; the Department of Anesthesiology, ${ }^{\mathrm{k}}$ Cardiothoracic Anesthesiology, Montefiore Medical Center, Bronx, NY; and the Department of Anaesthesiology and Intensive Care Medicine, ${ }^{1}$ Charité-Universitätsmedizin Berlin, Berlin, Germany.

Disclosures: The author group comprises the International Initiative on Haemostasis Management in Cardiac Surgery (IIHMCS). Members of the group were compensated for their presence at face-to-face meetings but not for the time invested in developing and reviewing the manuscript. Meeting organization and medical writing support for literature searches and manuscript preparation were provided by Physicians World Europe GmbH, Mannheim, Germany. Costs incurred for travel, hotel accommodation, meeting facilities, honoraria and preparation of the manuscript were supported by an unrestricted educational grant from Novo Nordisk Health Care AG, Zurich, Switzerland. The sponsor had no authorship or editorial control over the content of the meetings or any subsequent publication.

Drs Marco Ranucci and Solomon Aronson are co-first authors and cochairs of the International Initiative for Haemostasis Management in Cardiac Surgery (IIHMCS). Received for publication Jan 24, 2011; revisions received Feb 9, 2011; accepted for publication April 8, 2011; available ahead of print May 23, 2011

Address for reprints: Marco Ranucci, MD, Department of Cardiothoracic-vascular Anesthesia and Intensive Care, IRCCS Policlinico S. Donato, Via Morandi 30, San Donato Milanese, Milan, 20097, Italy (E-mail: cardioanestesia@ virgilio.it). $0022-5223 / \$ 36.00$

Copyright (c) 2011 by The American Association for Thoracic Surgery doi:10.1016/j.jtcvs.2011.04.007
}

products by examining the risk-benefit profile of blood product transfusion relative to the clinical condition of the patient. The risk-benefit profile of blood product transfusion depends on many factors but is primarily based on the hemoglobin value. Other important factors include patient age, sex, hemodynamic profile, and signs of organ dysfunction. ${ }^{5,6}$ The risks of infectious disease transmission ${ }^{1}$ and immunologic suppression, ${ }^{7}$ the costs, and a diminishing blood supply also contribute to the direct risk-benefit decision analysis and the overarching impetus to develop alternatives to blood component transfusion. The decision-making processe that determines whether to transfuse, when to transfuse, which blood products to transfuse, and how much of any product to transfuse are indeed complex and need to include an evaluation of both the risks of transfusion and perioperative anemia and a discussion about blood conservation strategies.

This topic was addressed by a comprehensive document on perioperative blood conservation in cardiac surgery released by the Society of Thoracic Surgeons and the Society of Cardiovascular Anesthesiologists. ${ }^{8}$ This document provides guidelines for the use of RBCs, fresh-frozen plasma, and platelets in the setting of a cardiac operation, providing appropriate hemoglobin cutoff values for erythrocyte transfusions, which vary widely depending on the clinical scenario. Although these guidelines address a number of very important issues and are largely followed in the structured context of clinical studies, the recommendations have not been widely accepted in clinical practice, as was recently demonstrated by a survey among anesthesiologists. ${ }^{9}$ This lack of acceptance may be attributable to a perceived lack of evidence, a lack of awareness of the guidelines, logistic issues related to the blood supply, institutional dogma, or policies that are based on economic considerations. Any or all of these factors may contribute to a reluctance to change institutional patient blood management.

The concept of patient blood management includes different strategies that aim to avoid unnecessary transfusions. The pillars that contribute to this concept are (1) the optimization of patient RBC mass, (2) the minimization of blood loss, and (3) the optimization of physiologic anemia tolerance. The comprehensive concept of patient blood management may soon replace the more simplistic 


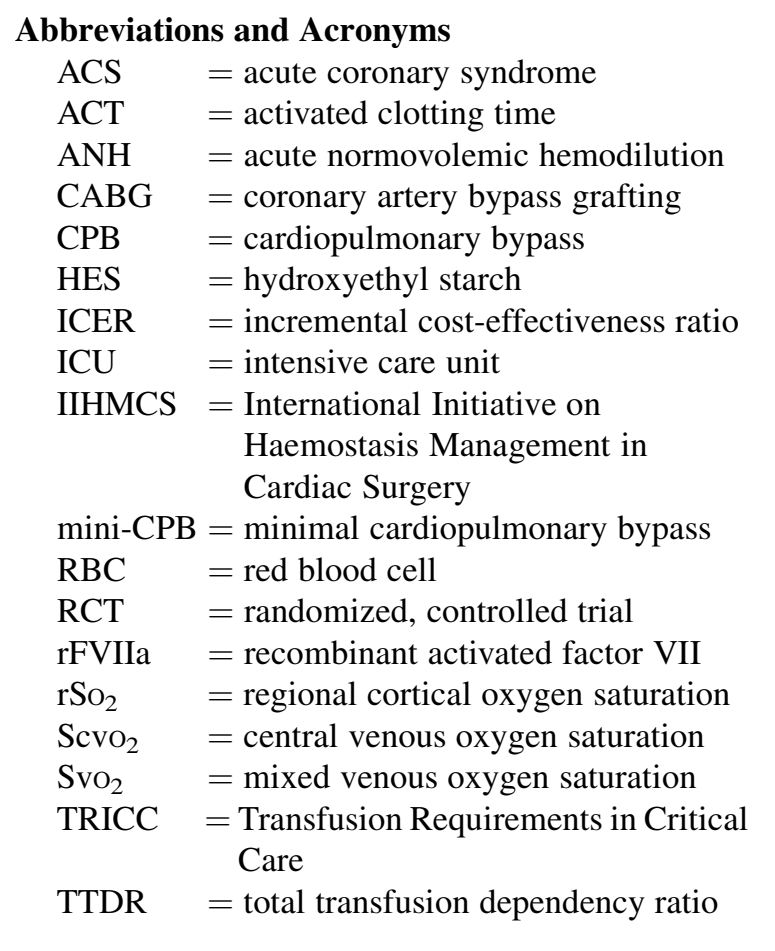

"transfusion containment" or "blood conservation" approaches.

At present, patient management is highly heterogeneous in different countries and institutions, and the recognition that allogeneic blood products may do harm does not seem to be widespread. A recent survey of nearly 25,000 patients undergoing coronary artery bypass grafting (CABG) in US institutions followed up from hospital admission until 30 days after discharge found large interinstitutional differences, accounting for $30 \%$ of the variance in transfusion practices. Allogeneic blood use ranged from 50\% to $100 \%$ among patients at different institutions, and $78.5 \%$ of the male and $93.6 \%$ of the female patients received allogeneic blood products during the hospital stay, implying that many of these transfusions may have been unnecessary. ${ }^{10}$ Similarly, a clinical trial comparing functional outcome after administration of a liberal versus restrictive transfusion regimen showed no benefit for the liberal transfusion group. ${ }^{11}$

The authors of this article comprise the International Initiative on Haemostasis Management in Cardiac Surgery (IIHMCS). We believe that many of the factors that influence the decisions and behavior surrounding transfusion of allogeneic blood products are not adequately addressed by the existing literature. One reason for this may be the lack of information available within existing databases used to determine the risk of transfusion during and after cardiac operations. Whereas traditional guideline and con- sensus papers review the weight of evidence to establish a rationalization for a position or plan of action, we have here sought to evaluate the evidence that exists to establish a "call to action" to fill the gaps and define the needs for further evidence.

The aims of this article are as follows: (1) to assess the level of evidence for indications and risk factors associated with transfusion of allogeneic RBCs and other blood products, (2) to identify evidence gaps and prioritize the evidence gaps with respect to potential impact on modifying practice and outcomes, and (3) to recommend possible actions to fill the evidence gaps, including but not limited to defining perioperative factors that should in future be included in existing databases.

\section{MATERIALS AND METHODS}

Comprehensive computer database literature searches were performed with the indexed online database MEDLINE/PubMed. Lists of cited literature within relevant articles and our own libraries were also screened. The primary intention of the review was to identify prospective randomized, controlled trials (RCTs), existing systematic reviews, and current guidelines. Boolean operators and Medical Subject Heading thesaurus keywords were applied as a standardized use of language to unify differences in terminology into single concepts. The scientific questions posed and the Medical Subject Heading headings applied to each search are listed in Appendix Table 1. Searches were limited to English-language abstracts and human studies, all in adults at least 19 years old, and the time period was limited to between January 1994 and April 2009. Full publications were retrieved on the basis of evaluated abstracts that were deemed relevant to the queries posed.

This author group comprises an international, multidisciplinary medical collaboration, the International Initiative on Haemostasis Management in Cardiac Surgery (IIHMCS), with both interest and expertise in the perioperative management of bleeding associated with cardiac surgery blood conservation and transfusion avoidance. The IIHMCS group includes members with specialties in cardiac surgery, cardiac anesthesia, hematology, and medical economics. As IIHMCS authors, we performed the selection of the scientific inquiries to be addressed, the screening and review of the literature to be included, the formulation of a summary of each section, and the complete manuscript review. The group participated in 2 face-to-face meetings in February and October 2009 and a web conference in July 2009 as part of the manuscript development process. The IIHMCS group was managed by Physicians World Europe GmbH, Mannheim, Germany, and its activities were supported by an unrestricted educational grant from Novo Nordisk Health Care AG, Zurich, Switzerland.

\section{RESULTS AND DISCUSSION Physiologic Signs of Organ Dysoxia}

Adequate organ oxygenation is fundamental for physiologic organ function. Normally, the amount of oxygen delivered to the whole body exceeds resting oxygen requirements by several fold. ${ }^{12}$ Tissue hypoxia occurs if oxygen delivery, defined as the product of arterial oxygen content and cardiac output, decreases to a level at which it is no longer adequate to meet the metabolic demands of the organs. Because hemoglobin-bound oxygen represents a major fraction of arterial oxygen content, increasing hemoglobin levels by RBC transfusion appears to be a logical 
strategy by which to improve oxygen delivery. The treatment or prevention of imminent inadequate tissue oxygenation is therefore a generally accepted indication for RBC transfusion. ${ }^{13}$ Blood transfusion aims to improve the oxygen transport capacity of the blood and therefore tissue oxygenation. It is not, however, clear whether more oxygen is actually delivered to the microcirculation after RBC transfusion. ${ }^{14,15}$

The evidence base on which RBC transfusion is performed is poor. Most RBC transfusions are administered because the hemoglobin concentration or hematocrit has fallen below a static, predefined threshold, which is perceived to be associated with an insufficient arterial oxygen content. This threshold varies widely between and even within institutions. Across different countries and institutions, $10 \%$ to $95 \%$ of patients undergoing cardiac surgery reportedly received blood transfusions, ${ }^{16-19}$ suggesting that many RBC transfusions, with their consequent transfusionassociated morbidity, may have been unnecessary.

Low preoperative hemoglobin concentrations and reduced intraoperative oxygen delivery have been shown to increase postoperative morbidity. ${ }^{20-22}$ In a retrospective study, low hematocrit was associated with worse outcome; however, transfusion, analyzed as a covariable, exacerbated this effect with an additional increase in morbidity. ${ }^{23}$ Detrimental effects of elevated hematocrit have also been demonstrated in a prospective observational study: a hematocrit of at least $34 \%$ on entry into the intensive care unit (ICU) was associated with higher rates of acute myocardial infarction, left ventricular dysfunction, and death after $\mathrm{CABG} .{ }^{24}$ Both an analysis of observational studies published between 1966 and June $2007^{25}$ and a more recent large cohort study ${ }^{26}$ showed that RBC transfusion is associated with increased perioperative and long-term morbidity and mortality, including renal dysfunction, bacteremia, surgical site infection, stroke, and prolonged ventilation.

From a clinical perspective, it is desirable to find more reliable and measurable predictors for adequate organ oxygenation. From the physiologic perspective, it is therefore worthwhile to replace the static hemoglobin transfusion trigger with a physiologic trigger that reflects the true oxygen demands of the body and of sensitive organs. ${ }^{27,28}$

Microcirculation. A review of the available literature shows controversial and confounding results, and in several studies RBC transfusion was not found to improve oxygen supply to specific organs. ${ }^{29}$ Experimental data suggest that the age of the transfused RBCs influences improvements in oxygen carrying capacity and microcirculation after blood transfusion $^{30}$ and that transfusion of older RBCs with impaired flexibility results in decreased oxygen upload in the lungs, diminished oxygen carrying capacity, and obstruction of tissue capillaries, with the consequence of impaired transfusion outcomes. ${ }^{31,32}$ In a study of patients with severe sepsis necessitating RBC transfusions, storage time had no influence on the microvascular response to RBC transfusion; however, an improvement in sublingual microcirculation by RBC transfusion was only seen in patients with altered capillary perfusion at baseline. ${ }^{33}$ In patients undergoing $\mathrm{CABG}$, duration of $\mathrm{RBC}$ storage was not associated with adverse outcome in some studies, ${ }^{34,35}$ whereas the transfusion of blood stored for longer than 14 days was associated with a significantly increased risk of postoperative complications in another study. ${ }^{36} \mathrm{Be}-$ cause data on the microcirculation were not reported in these studies, it remains unclear whether decreased oxygen uploading and diminished oxygen carrying capacity by older RBCs results in poor outcomes after transfusion in patients undergoing CABG. Clinically applicable methods for measurement of parameters of the microcirculation are not yet available. Effective therapeutic interventions to improve the microcirculation with drugs or fluids are being evaluated. ${ }^{37}$

Mixed venous and central venous oxygen saturations: Indicators of global body dysoxia. In clinical practice, hemoglobin concentration is used as a substitute for whole body oxygenation and thus as a trigger for blood transfusion. Hemoglobin concentration is, however, only a surrogate marker for oxygen-carrying capacity or oxygen supply. Mixed venous oxygen saturation $\left(\mathrm{Svo}_{2}\right)$, the oxygen saturation of venous blood in the pulmonary artery, may be a better physiologic marker of oxygen demand because it reflects the balance between systemic oxygen delivery and consumption. As clinical marker of systemic oxygen use, measurement of $\mathrm{SvO}_{2}$ continues to be a critical component of the hemodynamic monitoring of critically ill patients.

Patients who have undergone CABG exhibit a reduction in $\mathrm{SvO}_{2}$ during early postoperative mobilization, a reduction that may reflect reduced cardiac index and oxygen delivery at the same time that oxygen consumption is increased. The clinical consequences and underlying mechanism or mechanisms of the reduced $\mathrm{SvO}_{2}$ are not yet fully understood. ${ }^{38}$ Decreases in $\mathrm{SvO}_{2}$, however, have been associated with a poor prognosis in patients with septic shock ${ }^{39}$ or heart failure, ${ }^{40}$ and therapeutic interventions that aim to raise $\mathrm{SvO}_{2}$ have been tried during the resuscitation of critically ill patients.

Measurement of $\mathrm{SvO}_{2}$ requires placement of a pulmonary artery catheter. Because a central venous catheter is often inserted in critically ill patients for monitoring and fluid administration, measurement of central venous oxygen saturation $\left(\mathrm{ScVO}_{2}\right)$ may be an attractive alternative to monitoring of $\mathrm{SvO}_{2}$. Although the trend indicated by either measurement has demonstrated a clinical correlation in studies involving patients undergoing elective neurosurgical operations ${ }^{41}$ the disagreement between single measurements of $\mathrm{SvO}_{2}$ and $\mathrm{ScvO}_{2}$, such as was found in a study in cardiac surgical patients, ${ }^{42}$ may not always be clinically acceptable. 
The discrepancy between $\mathrm{ScvO}_{2}$, measured in the superior vena cava, and $\mathrm{SvO}_{2}$, reflects the differences in oxygen saturation between the superior vena cava, the inferior vena cava, and blood emanating from the coronary sinus. Measured values of $\mathrm{ScvO}_{2}$ depend heavily on the position of the catheter from which the blood is drawn, and differences in blood oxygen saturation measured at the proximal and distal ports of the pulmonary artery catheter may be related to measures of myocardial oxygen use. Further studies measuring coronary sinus blood oxygen content and flow are needed to test this hypothesis. ${ }^{43}$

The indications for measuring saturation by $\mathrm{ScvO}_{2}$ versus $\mathrm{SvO}_{2}$ have been the subject of much controversy. ${ }^{44}$ It has been argued that the utility of the latter parameter is limited: there are no correlations with regional tissue oxygenation, $\mathrm{SvO}_{2}$ provides no direct information about the relationship between oxygen delivery and uptake, the measurement is only valid during steady state, and no correlation exists between $\mathrm{SvO}_{2}$ and cardiac output. Studies comparing hemoglobin level with either $\mathrm{SvO}_{2}$ or $\mathrm{ScvO}_{2}$ as a transfusion trigger are not currently available.

The brain. Measurement of brain oxygenation has been the subject of a number of reviews. ${ }^{45}$ Many tools have been developed to estimate brain oxygenation. ${ }^{46}$ The use of nearinfrared reflectance spectroscopy for assessment of bifrontal regional cortical oxygen saturation $\left(\mathrm{rSO}_{2}\right)$ in patients undergoing $\mathrm{CABG}$ has demonstrated correlations between low $\mathrm{rSO}_{2}$ values and cognitive dysfunction, ${ }^{47,48}$ prolonged hospital stay, ${ }^{49}$ and perioperative cerebrovascular accidents. ${ }^{50}$ The cerebral oximeter has been used in a range of patients. Cerebral deoxygenation has been shown to correlate with a variety of adverse systemic outcomes, such as renal failure, prolonged ventilation, ${ }^{50,51}$ and physical workload. ${ }^{52,53}$

In one RCT, in many cases interventions to increase pump flow during cardiopulmonary bypass (CPB), increase mean arterial pressure, or normalize $\mathrm{PaCO}_{2}$ during CPB were sufficient to return $\mathrm{rSO}_{2}$ rapidly to within the baseline range; in others, however, multiple interventions were required at various intervals, with an overall success rate of only $80 \%{ }^{54}$ The decrease of $\mathrm{rSO}_{2}$ during acute normovolemic hemodilution (ANH) paralleled the decline of hemoglobin concentration; significant increases in tissue oxygenation in response to blood transfusion were also detected. Consequently, it has been speculated whether $\mathrm{rSO}_{2}$ might replace hemoglobin as a transfusion trigger. ${ }^{55}$ Extended exposure to levels of ANH to $5.1 \mathrm{~g} / \mathrm{dL}$ impaired cognitive function and delayed memory in healthy volunteers. This cognitive defect was reversible by retransfusion of autologous blood and by increasing the hemoglobin to $7.2 \mathrm{~g} / \mathrm{dL}{ }^{56}$ A comparable effect could be obtained by increasing the $\mathrm{PaO}_{2}$ by breathing $100 \%$ oxygen ${ }^{57}$ Animal studies did not confirm improved cerebral oxygenation by transfusion of stored blood. ${ }^{58}$ It is therefore conceivable that a decrease in $\mathrm{rSO}_{2}$ reflects insufficient oxygen uptake of brain tissue. It remains questionable, however, whether blood transfusion can indeed improve oxygenation.

The kidney. Severe anemia from any cause may produce congestive heart failure ${ }^{59}$ or result from heart failure. ${ }^{60}$ Vasodilatation caused by the accompanying tissue hypoxia lowers the blood pressure, thus activating the sympathetic nervous system. This causes peripheral vasoconstriction and tachycardia to maintain blood pressure. This in turn activates the renin-angiotensin-aldosterone system. The high angiotensin II levels further increase renal and peripheral vasoconstriction and increase aldosterone production. The resultant reduction in renal blood flow and glomerular filtration rate can cause renal ischemia and fluid retention. The renal insufficiency thus produced may in turn also cause anemia through reductions in erythropoietin production and erythropoietin bone marrow activity. ${ }^{12}$

Acute renal failure remains an important complication associated with cardiac and major surgery. The main cause is believed to be renal hypoperfusion and ischemia. ${ }^{61,62} \mathrm{Re}-$ nal vascular resistance is increased in relation to systemic vascular resistance during cardiac surgery, partly as a result of anemia, ${ }^{63}$ and this increase leads to a smaller fraction of cardiac output perfusing the kidneys. In addition, mean blood pressure is decreased, perfusion pressure is nonpulsatile, and renal blood flow autoregulation is not operative during $\mathrm{CPB} .{ }^{63}$ These factors conceivably influence the development of renal hypoperfusion and ischemia. Hemodilution during CPB may also contribute to postoperative renal dysfunction. ${ }^{20}$

On the basis of these considerations, it has been hypothesized that the perioperative use of a vasodilating agent, such as the calcium-channel blocker felodipine, could prevent the release of hypoxanthine during rewarming and that this prevention would be related to improved renal perfusion and oxygen supply. ${ }^{64}$ Renal uptake of the biomarker hypoxanthine or neutrophil gelatinase-associated lipocalin may be an indicator of maintained renal perfusion. ${ }^{64}$ Other therapeutic interventions are under discussion. ${ }^{65}$ "Online" real-time measurement of renal oxygenation, however, is not yet possible.

Splanchnic oxygen transport. Gut mucosal oxygenation, as assessed by noninvasive tonometry, has been shown to be a predictor of patient outcome in a variety of clinical settings, including heart surgery and intensive care. ${ }^{66}$ This is probably related to the fact that the gut is one of the first organ systems to undergo ischemic injury at times of hemodynamic stress. ${ }^{67}$ Moreover, the central role of impaired gut barrier function in driving the systemic inflammatory response syndrome and multiorgan failure would explain why gastrointestinal integrity is a predictor of outcome. It has been shown that although gastrointestinal complications are uncommon after $\mathrm{CPB}$, they are associated with very high mortality. ${ }^{68}$

Regional tissue hypoxia may develop despite apparently stable hemodynamics, as suggested by episodes of gastric 
TABLE 1. Common antithrombotics seen by the cardiac surgical patient

\begin{tabular}{|c|c|c|c|c|}
\hline Drug & Class & Physiologic half-life (h) & Timing relative to surgery & Reversibility \\
\hline Unfractionated heparin & Thrombin and FXa inhibitor & $1-1.5$ & $\begin{array}{l}\text { Can be administered up to skin } \\
\text { incision }\end{array}$ & Yes \\
\hline Low-molecular weight heparin & FXa and thrombin inhibitor & $2.5-4$ & Stop $12-24 \mathrm{~h}$ before incision & Partial \\
\hline Bivalirudin & Direct thrombin inhibitor & 0.5 & Stop 2 before surgery & $\begin{array}{r}\text { No, but rapidly } \\
\text { metabolized }\end{array}$ \\
\hline $\begin{array}{l}\text { Aspirin (INN acetylsalicylic } \\
\text { acid) }\end{array}$ & Cyclooxygenase inhibitor & Life of platelet & $\begin{array}{l}\text { Mildly controversial, usually } \\
\text { not discontinued }\end{array}$ & No \\
\hline $\begin{array}{l}\text { Clopidogrel bisulfate (INN } \\
\text { clopidogrel) }\end{array}$ & $\begin{array}{l}\text { Thienopyridine ADP receptor } \\
\text { antagonist }\end{array}$ & Life of platelet & $\begin{array}{l}\text { Guidelines: stop } 5 \text { days before } \\
\text { surgery; practice: variable }\end{array}$ & No \\
\hline Ticlopidine hydrochloride & $\begin{array}{l}\text { Thienopyridine ADP receptor } \\
\text { antagonist }\end{array}$ & Life of platelet & Same & No \\
\hline Prasugrel hydrochloride & $\begin{array}{l}\text { Thienopyridine ADP receptor } \\
\text { antagonist }\end{array}$ & Life of platelet & Unclear, more data needed & No \\
\hline Abciximab & GP IIb/IIIa receptor antagonist & Life of platelet & Stop $24 \mathrm{~h}$ before incision & $\begin{array}{l}\text { Platelet transfusion } \\
\text { may partially reverse } \\
\text { (controversial) }\end{array}$ \\
\hline Eptifibatide & GP IIb/IIIa receptor antagonist & $4-6$ & Stop 6-12 h before surgery & No \\
\hline Tirofiban & GP IIb/IIIa receptor antagonist & $4-6$ & Stop 6-12 h before surgery & No \\
\hline
\end{tabular}

Fxa, Activated factor Xa; $A D P$, adenosine diphosphate; $G P$, glycoprotein.

mucosal acidosis in as many as $50 \%$ of patients after cardiac surgery. ${ }^{69}$ The increasing metabolic demand during the immediate postoperative period may increase the risk of tissue hypoxia. It has been demonstrated that the increasing metabolic demand is compensated for by a combination of increased oxygen extraction and blood flow, both in the whole body and in the splanchnic region, and that the regional oxygen extraction capability is well preserved for a long period. ${ }^{70}$ The gastric mucosal $\mathrm{pH}$ continues to decrease, reaching its nadir several hours postoperatively. ${ }^{71}$ This suggests that a regional mismatch between oxygen delivery and demand may persist or develop after the stabilization of systemic hemodynamics in the postoperative period. $^{72}$ More recent data, ${ }^{73}$ however, have shown that intestinal perfusion is sufficiently preserved with moderate hemodilutional anemia caused by CPB (hematocrit $25 \%$ $33 \%$ ). Furthermore, in a prospective, randomized trial, more profound hemodilution (hematocrit $20 \%$ vs $25 \%$ ) during normothermic CPB did not induce an increase in gastrointestinal permeability, which is a surrogate parameter for maintained gastrointestinal perfusion and oxygen delivery. ${ }^{74}$

Areas of uncertainty and topics for further study. Organ dysoxia is a leading cause of organ dysfunction, but hemoglobin content is a poor surrogate marker for impaired organ oxygenation. For the heart, and with limitations the brain, direct markers of deoxygenation are measurable online. For total oxygen consumption and thus for body dysoxia, $\mathrm{SvO}_{2}$ is the best available indicator. Although it is still under debate in cardiac surgery whether $\mathrm{ScvO}_{2}$, in clinical practice may substitute for $\mathrm{SvO}_{2}$, both are global parameters that do not reflect regional oxygen supply. To what extent an increase in hemoglobin concentration as a result of transfusion enhances tissue and organ oxygenation is unclear and still under investigation. To date, a combination of physiologic transfusion triggers and hemoglobin concentration, as suggested by Spahn and others, ${ }^{28,75}$ may best guide improvement of organ oxygenation, but further research is needed.

\section{Clinical Assessment and Decision Making}

Management of the underlying disease process affects cardiac surgical bleeding, especially for patients with acute coronary syndrome (ACS) who have intracoronary thrombosis. Treatment of these patients involves intense and aggressive antithrombotic treatment on presentation. ${ }^{76,77}$ Approximately $10 \%$ of patients with ACS will undergo surgical revascularization, and management of these patients can be challenging because they are exposed to a variety of antithrombotic agents, including platelet inhibitors (cyclooxygenase inhibitors, thienopyridines, glycoprotein IIb/ IIIa inhibitors) and anticoagulants (Table 1). In addition, patients may receive thrombolytic agents before surgery. Exposure to these antithrombotic agents increases the risks of perioperative bleeding, transfusions, and surgical reexploration for persistent hemorrhage or cardiac tamponade. In clinical decision making for this patient population, it is extremely important to minimize risk and improve patient safety. Important clinical decisions include the timing of surgery for patients exposed to antithrombotic agents before surgery, the use of pharmacologic adjuncts to support hemostasis during surgery, the timing of transfusion, and the type of blood products transfused. When bleeding does occur, the etiology can be difficult to diagnose. Advanced laboratory 
testing of the patient's hemostatic potential may be helpful in clarifying the cause of bleeding, although practice patterns remain highly variable. Thrombelastometry as a point-ofcare test potentially allows earlier diagnosis of hemostatic abnormalities and specific identification of the type of disturbances present during cardiac surgical procedures. ${ }^{78}$ Other, more platelet-specific, point-of-care tests are also available to identify the severity and cause of platelet dysfunction, although the effectiveness of these tests in reducing transfusion remains unclear.

The timing of surgery. In patients with ACS, the optimal timing of surgery can be a difficult clinical decision. The decision as to when to discontinue antithrombotic agents will depend on the pharmacodynamic half-life for each agent as well as on the potential lack of reversibility. ${ }^{8}$ For anticoagulant therapy, this decision is relatively straightforward and can be based on extensive clinical experience. Low-molecular weight heparins should be discontinued 12 to 24 hours before surgery to avoid excessive bleeding, ${ }^{8}$ because the anticoagulant effect of low-molecular weight heparins may be intense and is only partially reversible. Patients receiving unfractionated heparin preoperatively are easier to manage because reversal of the antithrombin effect with protamine is possible; many surgeons therefore do not discontinue unfractionated heparin before CABG.

The optimal timing of surgery in patients exposed to antiplatelet agents is more difficult, because the effects of many platelet inhibitors are irreversible or long acting, and the potency of their platelet inhibition may be variable. Although preoperative aspirin (INN acetylsalicylic acid) affects perioperative bleeding and transfusion, its effect on the surgical patient is usually small. For the vast majority of patients with ACS requiring urgent $\mathrm{CABG}$, continuing aspirin until surgery thus seems to be the best option. Aspirin is therefore rarely discontinued before coronary revascularization. ${ }^{8} \mathrm{~Pa}-$ tients on an aspirin regimen who undergo surgery are usually treated with platelet transfusion only when bleeding is problematic, although the optimal timing and magnitude of transfusion is unclear. A delay of 7 to 10 days to allow for platelet function to normalize is impractical and risky for all but the most elective cardiac surgical cases, and for most patients aspirin is continued throughout the perioperative period because the benefits of aspirin outweigh its small impact on the need for transfusion.

The management of patients treated with more potent antiplatelet medications is controversial. Glycoprotein IIb/IIIa inhibitors can be divided into relatively shortacting agents, such as eptifibatide and tirofiban, and longacting ones, such as abciximab. The shorter-acting agents should optimally be discontinued 2 half-lives before surgery (approximately 4-6 hours) The longer-acting glycoprotein IIb/IIIa inhibitor abciximab should be discontinued 24 hours before surgery to avoid excessive bleeding and transfusion. ${ }^{79,80}$
Management of patients exposed to thienopyridines before surgery is also controversial. Analysis from a large clinical trial of patients presenting with ACS without STsegment elevation suggests that patients undergoing CABG more than 5 days after exposure to aspirin and the thienopyridine clopidogrel bisulfate (INN clopidogrel) had no increased risk of blood loss, whereas patients who underwent surgery within 5 days of exposure had a (not significantly) increased risk of major bleeding. ${ }^{81}$ In a more recent retrospective cohort analysis, patients with ACS undergoing CABG within 5 days of receiving clopidogrel bisulfate had a significantly increased risk for major bleeding. ${ }^{82}$ Accordingly, guidelines from the Society of Thoracic Surgeons recommend a 5- to 7-day washout period after exposure to thienopyridine before surgery to reduce the risk of bleeding. ${ }^{8}$

Delayed surgery for a patient with ischemic heart disease is associated with risks, however, and many surgeons and cardiologists are uncomfortable with long delays between catheterization and surgical revascularization and may proceed with urgent CABG despite increased bleeding risk. These patients also usually remain hospitalized until the operation, with associated costs. In addition, the optimal waiting period for washout of the thienopyridine is unclear, because the individual patient response to clopidogrel bisulfate is variable. Although guidelines recommend a washout period of at least 5 days, a recent investigation suggested that a shorter interval of only 3 days may be equally safe, avoiding the increase in bleeding and transfusion that occurs when no washout interval is implemented. ${ }^{83}$

Prasugrel hydrochloride is a recently approved thienopyridine for patients with ACS that has a rapid onset of action and a potent, more consistent, and long-lasting antiplatelet effect. ${ }^{84}$ The combination of prasugrel hydrochloride and aspirin demonstrated superior efficacy to that of clopidogrel bisulfate and aspirin; however, non-CABG-related major, life-threatening, and fatal bleeding was also found to be significantly higher. ${ }^{84}$ Patients with a history of stroke, elderly patients, and small patients had higher rates of severe and life-threatening bleeding when treated with prasugrel hydrochloride. Also, patients who underwent CABG had a 4-fold higher incidence of major bleeding when exposed to prasugrel hydrochloride relative to clopidogrel bisulfate. The optimal management algorithm for patients undergoing surgery exposed to prasugrel hydrochloride is unclear, because experience with the drug is limited; however, postponing surgery for 5 to 7 days (the life of the platelet) seems prudent when possible. Whether different management strategies and a longer washout interval are needed for patients exposed to prasugrel hydrochloride as opposed to clopidogrel bisulfate or ticlopidine hydrochloride remains unclear and will require further investigation.

Not surprisingly, registry data have documented significant practice variability among surgeons caring for patients 
exposed to platelet inhibitors. ${ }^{85}$ In addition, a post hoc analysis from a large ACS trial suggests that preoperative dual platelet inhibition may actually reduce postoperative ischemic events such as myocardial infarction, possibly by limiting microembolization in the vascular tree. ${ }^{86}$ Although platelet function tests are available and would intuitively seem useful, many clinical questions remain regarding their actual utility to guide clinical decision making, including which test to use, what degree of platelet inhibition is safe for surgery, and how to manage patients with clinically relevant inhibition of platelet function. These open questions are areas of active clinical research and product development.

Timing of transfusion of RBCs and other blood products. The optimal trigger to transfuse packed RBCs during or after surgery is unclear. Although guidelines exist, many surgeons individually tailor therapy and transfuse blood according to a clinical analysis that takes into account a patient's age and relative health, specifically a history of stroke, neurologic impairment, and heart or other major organ failure. Many surgeons and other clinicians consider transfusion when the hematocrit falls below a certain threshold, such as $21 \%$ or $24 \%$, although these values are rather arbitrary, and healthy patients can certainly tolerate greater degrees of anemia. A better understanding of the decisionmaking process behind the patient-specific use of RBC transfusion is an important area of future clinical research.

The timing of transfusion in patients at high risk for bleeding is also not clear. Prophylactic transfusions of platelets have been suggested for patients exposed to abciximab, ${ }^{87}$ usually after discontinuation of CPB. For patients exposed to thienopyridines or aspirin, many surgeons use a "wait and see" approach that depends on clinical events and the magnitude of postoperative chest tube drainage. Regardless of the antiplatelet medication used, the decision to transfuse platelets is relatively arbitrary and is based on clinical assessment, without laboratory confirmation of systemic platelet dysfunction. Results from a small study suggest that near-patient impedance aggregometry measurements may allow the identification of patients with enhanced risk of platelet concentrate transfusion. ${ }^{88}$ Whether specific platelet-directed functional analysis in the bleeding patient will limit empiric platelet transfusion is unclear, however, and is discussed in another section of this article.

Areas of uncertainty and topics for further study. The management of patients exposed to anticoagulants before surgery remains an area of significant practice variability and unanswered questions. Future topics for study include the identification of an optimal time to proceed with surgery after the suspension of antithrombotic medications and the use of point-of-care laboratory testing to guide the timing of surgery.

\section{Perioperative Fluid and Hemodilution Management} ANH (intraoperative autologous donation). ANH is a technique that removes whole blood while maintaining euvolemia immediately before operation. It is inexpensive and efficient, it may preserve coagulation factors, and it nearly eliminates clerical error. In theory, the method preserves withdrawn blood from CPB degradation, decreases the amount of autologous components lost to bleeding, and provides fresh autologous whole blood for reinfusion after CPB. ANH does not reduce bleeding but does appear to reduce the need for allogeneic blood transfusions. ${ }^{89-97}$

The efficacy of ANH is limited by several factors, around which a number of questions remain for future investigation, including the target for acute hemodilution, transfusion triggers, and fluid type required to establish optimal ANH. In a recent prospective RCT of hemodilution during cardiac surgery with hypothermic $\left(30^{\circ} \mathrm{C}-32^{\circ} \mathrm{C}\right) \mathrm{CPB}$ in adults, in which a target hematocrit of $27 \%$ was compared with a target hematocrit of $17 \%$, it was noted that neurocognitive impairment was increased after extreme hemodilution. ${ }^{98}$ Although it has been suggested that blood loss should exceed $70 \%$ of patient blood volume for ANH to prevent homologous transfusion of at least $1 \mathrm{RBC}$ unit, ${ }^{99}$ an optimal starting hemoglobin level has not been established, nor has an optimal transfusion trigger. Clinical studies have suggested that patients with cardiovascular disease can tolerate hemoglobin levels of $7.0 \mathrm{~g} / \mathrm{dL}^{11,100}$ and that hemodilution does not alter the coronary vasodilating effects of endogenous or exogenous nitric oxide. ${ }^{101}$ The effect of acute reduction in circulating hemoglobin levels by ANH combined with significant surgical blood loss remains in question, however, and the safe limits of hemodilution have not been established.

To provide better understanding of the risks and benefits of $\mathrm{ANH}$, future investigation should focus on identifying safe hemodilution limits according to patient subtype, along with specific situational and conditional circumstances. For example, a 40-year-old man without comorbidity may have a different hemodilution target tolerance or transfusion trigger threshold than a 70-year-old man with multiple comorbidities.

Preoperative autologous RBC blood donation. Although the safety of blood supplies is high in developed countries, there is still concern about contraction of infections from transfusion of allogeneic blood. Preoperative autologous blood donation is the process by which patients donate blood before elective surgery and subsequently receive their own blood in the perioperative period if transfusion is required. Theoretic advantages include the patient's sense of control over care, decreased risk of direct transmission of viral infections, and avoidance of alloimmunization from donor blood. Disadvantages include the inconvenience of donation weeks before the procedure, considerable operating costs, an inherent delay that may lead to decreased effectiveness of stored blood oxygen delivery, and an increased need for adequate replacement of lost $\mathrm{RBC}$ mass before surgery. There also remains a risk of 
clerical error. Overtransfusion may be a serious risk, especially for older people.

In a meta-analysis of 15 studies conducted in the 1980 and 1990, preoperative autologous blood donation decreased exposure to allogeneic blood but increased exposure to any transfusion (allogeneic, autologous, or both) ${ }^{102}$ This result may have arisen because preoperative autologous blood donation caused some preoperative anemia or because of a more liberal transfusion policy when autologous blood was available. In a recently published Cochrane metaanalysis, the relative risk reduction for receiving an allogeneic blood transfusion was $68 \%$ in patients with preoperative autologous blood donation relative to control groups, with an absolute risk reduction of $44 \%$. The risk of receiving any blood transfusion (allogeneic, autologous, or both) was actually increased by preoperative autologous blood donation (relative risk $1.24,95 \%$ confidence interval $1.02-1.51){ }^{103}$

Only a single trial has assessed preoperative autologous blood donation in cardiac surgery. ${ }^{104}$ In this small, prospective study, exposure to allogeneic blood products was $39.1 \%$ in the control group not undergoing preoperative autologous blood donation, whereas $47.8 \%$ of patients in the preoperative autologous blood donation group received any blood product $(P=.73$ ), including $16 \%$ exposed to allogeneic blood products $(P=.036$ vs control).

The optimal method, amount, timing before surgery, and most cost-effective approach to autologous blood donation remain undefined. Although the trials of preoperative autologous blood donation have shown a reduction in the need for allogeneic blood, the methodologic quality of these trials was poor, and for most trials covered in the Cochrane meta-analysis, ${ }^{103}$ allocation concealment was not described. Because the overall transfusion rates were increased by recruitment into the preoperative autologous blood donation arms of the trials, these data raise questions about the benefit of preoperative autologous blood donation. In the absence of large, high-quality trials with relevant clinical end points, it is not possible to determine whether the benefits of preoperative autologous blood donation outweigh the harms. Because bias for the success or failure of this technique has become more and more institutionally specific in recent years, ${ }^{105}$ targeted studies that explore transferable assumptions from any given institution to another may be needed.

Acute preoperative platelet pheresis. Acute preoperative platelet pheresis comprises withdrawal of autologous platelet rich plasma immediately before surgery and reinfusion after CPB. Several prospective randomized studies have shown conflicting results for the efficacy of acute preoperative platelet pheresis in limiting bleeding and blood transfusions after cardiac surgery, ${ }^{106-118}$ and a metaanalysis concluded that acute preoperative platelet pheresis was only marginally effective in trials of good quality. ${ }^{119}$

Despite some laboratory evidence of preserved coagulation and fibrinolytic parameters, the clinical evidence does not generally support this technique to reduce bleeding or transfusion. It has been suggested that lack of standardization may play a role, because some techniques result in high-yield platelet salvage whereas others do not. ${ }^{19,120}$ The effectiveness of techniques that provide high-yield platelet salvage to reduce bleeding or transfusion remains to be demonstrated.

Hemostatic defects during cardiac surgery are influenced by several mechanisms, including inhibition of platelet aggregation and fibrinolysis. Heparin cannot completely prevent generation of thrombin or fibrin, ${ }^{109}$ and it is not clearly understood why acute preoperative platelet pheresis appears to contribute to the stabilization of impaired platelet function according to laboratory but not to clinical intravascular hemostasis. Furthermore, it may be questionable whether acute preoperative platelet pheresis is still effective to reduce blood loss and transfusion requirements in times of dual antiplatelet inhibition.

It appears that our assumptions and rationalizations regarding platelet and coagulation medicine are incomplete and inadequate at this time. More basic research is needed for a better understanding of why this technique does or does not translate into the fulfillment of clinical reality.

Alternative volume replacement solutions, including postoperative fluid management. Alternative intravascular fluid volume expansion options comprise fluids other than crystalloid solutions. Overall, the data show that colloids maintain intravascular volume and regional tissue perfusion better than do crystalloids, but there are differences among colloids when used for fluid management in acutely ill patients with respect to the incidence of adverse events. All hydroxyethyl starch (HES) solutions modify coagulation function by interfering with fibrinogen, factor VIII, von Willebrand factor, platelet function, fibrin formation, and clot firmness. The degree of hemostatic impairment caused by HES depends on the molecular weight, degree of substitution, and rate and volume of infusion. A new generation of more easily degraded HES solutions of medium or lower molecular weight has therefore been developed to result in fewer effects on hemostasis while providing a similar volume-expanding effect. ${ }^{121-126}$ Gelatins have unlimited dose recommendations but are associated with allergic reactions ${ }^{127-129}$ and exhibit comparable effects on the coagulation system. ${ }^{127-130}$ Human albumin has a negligible effect on coagulation but is expensive, in short supply, and itself a blood product. ${ }^{131}$

A number of studies have assessed the effect of the choice of resuscitation fluid for patients in ICUs. In a multicenter, double-blind RCT in a heterogeneous population of ICU patients, the use of either $4 \%$ albumin or normal $0.9 \%$ saline solution for fluid resuscitation resulted in similar outcomes at 28 days; however, effects on bleeding and transfusion were not reported. ${ }^{132} \mathrm{~A}$ meta-analysis of 21 studies in adult and pediatric patients undergoing cardiac and noncardiac 
surgery indicated that relative to crystalloids albumin as a priming solution was associated with a lower drop in platelet count and with a less positive fluid balance during $\mathrm{CPB}$, which resulted in a lower postoperative weight gain. ${ }^{133}$ There was no benefit reported when albumin was added to synthetic colloids in adult cardiac surgical patients. ${ }^{134}$

In view of the lower costs of synthetic colloids, their use has been considered a valuable alternative to albumin. In a pooled analysis of 7 studies in major surgery that included 4 cardiac surgical trials, blood loss and transfusion requirements were lower for patients receiving HES 130/0.4 than for those receiving HES 200/0.5. ${ }^{135}$

It remains uncertain when or whether the choice of resuscitation fluid may affect perioperative bleeding or transfusion requirements. RCTs that are carefully designed to distinguish patient subtype, situation, and condition are needed. For example, a 40-year-old man without comorbidity during a low- or moderate-risk procedure may have a different response (hemodilution target tolerance or transfusion trigger threshold) than a 70-year-old man with multiple comorbidities undergoing a high-risk procedure.

Areas of uncertainty and topics for further study. Future investigation should focus on developing RCTs that identify patient subtypes and both situational and conditional circumstances that influence the risk-benefit ratio associated with ANH. Database analyses would facilitate more targeted hypothesis generation to improve patient selection criteria. In addition, exploration of newly developed database sources, including health economic parameters, would allow observational research to advance knowledge in this area. Methodologic standardization of acute platelet plasmapheresis to establish procedural norms is also needed. The available studies provide inadequate data from which to draw firm conclusions regarding the effect of acute platelet plasmapheresis on clinically important end points, and further study is required.

\section{Cardiopulmonary Bypass}

Pump type: Centrifugal versus roller. Centrifugal pumps are nonocclusive pumps that produce a constrained vortex by rotation of impellers or concentric bells. Roller pumps are occlusive pumps that sequentially compress a segment of the CPB circuit.

Platelet count and function are better preserved by centrifugal pumps. ${ }^{136,137}$ It is therefore possible that these pumps could limit postoperative bleeding and transfusions. There are no RCTs demonstrating that centrifugal pumps reduce transfusion rate or the amount of blood products used, perhaps because it is difficult to separate "pump effect" from other confounders, because centrifugal pumps are always used in the context of other techniques such as minimal CPB (mini-CPB). Centrifugal pumps therefore appear to be safer than roller pumps, but if used separately from other techniques, pump type appears not to limit transfusions.

Shed blood management: Closed versus open circuits. Closed circuits are circuits with a collapsible venous reservoir and cardiotomy reservoir separated from the venous line or circuits without a cardiotomy reservoir. Blood processing includes washing and concentrating RBCs with a cell saver. The air-blood interaction is a determinant of platelet activation and hemolysis. Shed blood (blood collected in the pericardial cavity) is conveyed into a cardiotomy reservoir and readministered to the patient when an open circuit is used. This blood contains many products that can activate the inflammatory, hemostatic, and fibrinolytic systems and can promote platelet activation. ${ }^{138-142}$ It has therefore been hypothesized that the use of closed circuits with shed blood washing may limit postoperative bleeding and the related transfusion needs.

There have been few studies to address the impact of closed circuits on transfusion rates. Two studies ${ }^{143,144}$ found no significant differences in transfusion rate. One RCT addressing the effects of cardiotomy blood processing during and after CPB described no differences in transfusion rate but did note a higher number of units transfused in the group in which the cardiotomy blood was processed. ${ }^{144}$ In contrast, an earlier study ${ }^{145}$ demonstrated that shed blood processing resulted in less postoperative bleeding, with a trend toward fewer allogeneic blood transfusions.

Too few RCTs have investigated shed blood management with respect to transfusion rates. Moreover, most of the published studies include confounders implemented together with closed circuits, such as biocompatible coatings, reductions in systemic heparinization, and centrifugal pumps. The possibility remains that blood processing may be detrimental because of the loss of coagulation proteins.

Surface treatment of circuit and oxygenator. Surface treatment of circuit and oxygenator includes any chemical treatment that aims to increase the biocompatibility of CPB materials. Much evidence exists that surface treatments of $\mathrm{CPB}$ materials decrease the inflammatory response to $\mathrm{CPB},{ }^{146-151}$ limit hemostatic activation, ${ }^{147,152}$ and preserve platelet function, ${ }^{148,153,154}$ even if thrombin generation does not appear to be directly affected by these treatments. ${ }^{155}$ It is therefore reasonable to hypothesize that surface treatments would decrease allogeneic blood product transfusion rate through a combination of these effects.

Approximately 40 RCTs have addressed the clinical impact of CPB surface treatments on outcome after cardiac surgical operations. The two largest RCTs ${ }^{156,157}$ failed to identify significant differences in transfusion rates. Two recent meta-analyses pooled the data from the available RCTs. ${ }^{158,159}$ The first, ${ }^{158}$ which was limited to heparinbonding treatments and included 19 RCTs (2709 patients) in the transfusion rate pooled analysis, concluded that the 
use of heparin-bonded circuits was associated with a significant reduction in blood transfusion rate. The second analysis, ${ }^{159}$ which pooled all the different surface treatments and analyzed 20 RCTs (3453 patients), again found a significant reduction in blood transfusion rate. When only the high-quality studies were considered, however, the difference was no longer significant.

Although much information can be gathered from the current literature with respect to CPB surface treatment and transfusion rates, most studies to date have not included a well-defined transfusion protocol and are heterogeneous with respect to the other material-independent sources of blood activation, such as circuit type and heparin management.

Reduced systemic heparinization. Anticoagulation to establish and maintain CPB may be achieved with a heparin loading dose less than $300 \mathrm{IU} / \mathrm{kg}$, with a target activated clotting time (ACT) of at least 300 seconds, in association with the use of biocompatible circuits and oxygenators. Current heparinization practice (300-400 IU/ $/ \mathrm{kg}$ with a target ACT of at least 400 seconds) is based more on tradition than on evidence. One $\mathrm{RCT}^{160}$ demonstrated that a loading dose of $200 \mathrm{IU} / \mathrm{kg}$ of heparin is sufficient to reach a target ACT of 480 seconds, and that patients receiving less heparin had a lower postoperative blood loss. Reduction of systemic heparinization with heparin-coated circuits decreases platelet activation. ${ }^{161}$ It is reasonable to hypothesize that by decreasing the heparin dose and, as a consequence, the protamine dose, both bleeding and transfusions may be reduced.

A number of studies have demonstrated that reduced systemic heparinization in association with biocompatible circuits is feasible and safe. ${ }^{161-168}$ A limited number of RCTs have explored the impact of this technique on transfusion rates. One RCT found no significant differences, ${ }^{162}$ whereas others ${ }^{165,167}$ found a significant reduction in transfusion rate.

The current evidence is based on the association between biocompatible circuits (mainly heparin-bonded circuits) and reduced systemic heparinization. No evidence exists that the heparin dose and the target ACT can be safely reduced with conventional circuits. More RCTs are required to clarify the impact of this technique on transfusion needs, but a trend towards a beneficial effect exists. We suggest that future studies focus more on the concept of "adequate heparinization" rather than "reduced heparinization," with heparin concentration monitoring systems included in the study design. Relevant fields to be included in the databases are as follows: (1) heparin loading dose, (2) subsequent heparin doses, (3) target ACT, and, whenever available, (4) heparin sensitivity $(\mathrm{s} /[\mathrm{IU} \cdot \mathrm{kg}])$. It may also be worthwhile to measure thrombin generation, for example by thrombinantithrombin complexes or prothrombin fragment 1.2.
Hemodilution during CPB: Reduction techniques. Hemodilution during CPB is the lowest hematocrit or hemoglobin value reached during CPB. Regardless of the transfusion protocol applied, transfusions are always triggered by levels of hemoglobin considered inadequate for the patient's needs. Because of the CPB priming solution, additional fluids, and cardioplegia, various degrees of hemodilution may be tolerated during CPB. It is reasonable to hypothesize that low hematocrit values during $\mathrm{CPB}$ may trigger transfusions during $\mathrm{CPB}$ and may result in a low hematocrit in the early postoperative phases, triggering postoperative blood transfusions. Measures that aim to limit hemodilution during CPB thus could limit both intraoperative and postoperative transfusions.

Large database investigations have found an association between the lowest hematocrit during CPB and postoperative morbidity and mortality. ${ }^{20,169-174}$ Correction of hemodilution with allogeneic blood transfusions, however, may exacerbate the problem. ${ }^{20,171}$ Reduction of the CPB priming volume may help to limit hemodilution during CPB. This can be achieved by minimizing tubing size and length and using vacuum-assisted venous drainage or retrograde autologous priming. A $2007 \mathrm{RCT}^{175}$ demonstrated that reducing priming volume from 1400 to $800 \mathrm{~mL}$ resulted in a significantly lower rate of allogeneic blood transfusions. Another study in $2006^{176}$ had found similar results.

Measures to reduce hemodilution during CPB are reasonable and are often achieved by using mini-CPB in conjunction with other techniques. A priming volume reduction may be achieved, however, even with conventional CPB circuits.

Minimal CPB. Mini-CPB comprises the following simultaneous conditions: closed circuit (with or without collapsible venous reservoir), centrifugal pump, reduced $(<1000$ $\mathrm{mL}$ ) priming volume, biocompatible surface treatment, and shed blood separation. Reduced systemic heparinization may also be applied. Mini-CPB includes several strategies that have a recognized or hypothesized effect on allogeneic blood transfusions, so it is reasonable to hypothesize that mini-CPB might show some synergistic effects.

At present, $8 \mathrm{RCTs}^{175-182}$ have investigated transfusion rates in patients undergoing mini-CPB relative to a control group. Five of these studies ${ }^{175-179}$ found a significant beneficial effect, whereas 3 of them ${ }^{180-182}$ found no differences, mainly because of a limited patient population. A recent meta-analysis of RCTs ${ }^{183}$ demonstrated that mini-CPB is associated with a $60 \%$ reduction in blood transfusions (odds ratio $0.4,95 \%$ confidence interval 0.26-0.63). MiniCPB is a technique associated with a high level of evidence for the limitation of blood transfusions.

Areas of uncertainty and topics for further study. There are still areas of uncertainty about the role of CPB technique and equipment in determining the transfusion needs. The 
role of closed versus open circuits has still not been fully elucidated, and this is reflected in the widespread clinical use of both systems. Larger studies on mini-CPB (which incorporates closed circuits) are needed. The main debate, however, still revolves around the optimal dose and monitoring of heparinization and heparin reversal.

\section{Adverse Outcome After Transfusion}

The treatment aim of RBC transfusion is to reverse or prevent incipient tissue hypoxia arising as a consequence of acute hemorrhage or severe anemia. The efficacy of transfusion in achieving this goal, however, has never been evaluated in a high quality randomized study in cardiac surgery. What evidence we have is largely derived from observational clinical studies. Rather than show that transfusion is efficacious, these studies appear to show an apparently paradoxic association between RBC transfusion and adverse outcome. Data from studies evaluating associations between transfusion and perioperative mortality, sepsis, and ischemic syndromes, including cardiac and renal complications, ${ }^{1,2,10,21,23,26,65,184-199}$ are summarized in Figures 1 through 4.

Typically, these types of analyses use statistical approaches to adjust for such confounding variables as differences in risk profiles between transfused and nontransfused patients. The analyses cannot, however, adjust for unmeasured confounders or for the likelihood that there will have been bias in the prescription of allogeneic RBCs, with patients who are more ill being more likely to receive transfusions than those who are less ill. There is also a tendency toward reporting bias in these types of analyses. As such, we cannot claim that the data displayed in Figures 1 through 4 demonstrate causality. The significant heterogeneity in the definitions of intervention (transfusion yes or no, massive transfusion yes or no, number of units as a continuous variable) as well as in definitions of outcomes in these studies precludes quantitative meta-analyses. A qualitative review of the data, however, demonstrates consistent and large effect sizes for associations between transfusion and adverse outcomes across studies and in different populations, and these are unlikely to be attributable simply to confounding and bias. This data, it could be argued, are sufficient to present an ethical barrier to high-quality randomized trials that might attempt to demonstrate a causal relationship between transfusion and adverse outcome. When one considers that as many as $100 \%$ of patients receive allogeneic blood components in some centers, it could also be argued that this level of evidence is not considered enough to justify restrictive transfusion practice by many clinicians. This represents objective evidence of clinical equipoise. Moreover, if transfusion does cause adverse events, there is a clinical responsibility to demonstrate this. This is a rationale for a multicenter randomized trial designed to demonstrate a causal relationship between transfusion and adverse outcome.
Such a trial would presumably be designed along the lines of the pivotal Transfusion Requirements in Critical Care (TRICC) study published more than a decade ago. ${ }^{200}$ This remains the only high-quality RCT that has sought to detect differences in clinical efficacy between 2 transfusion indications in adults, and it offers some evidence that transfusion causes organ injury. This study, performed in critical care patients, compared a restrictive transfusion threshold $(7.0 \mathrm{~g} / \mathrm{dL})$ with a liberal transfusion threshold $(10.0 \mathrm{~g} / \mathrm{dL})$. A total of $100 \%$ of those in the liberal group received an allogeneic RBC transfusion, compared with $67 \%$ in the restrictive group. Although there was no difference in the primary end point (30-day mortality) between the groups, there were some differences in secondary end points, including myocardial infarction and pulmonary edema. Allogeneic RBC storage methods have progressed in the last decade, with universal leukodepletion being used in many countries, and there is limited homology between the highly selected group of patients randomly allocated in TRICC and those undergoing cardiac surgery. For example, the TRICC patients were on average at least 10 years younger than those reported in most series in adult cardiac surgery, and only $20 \%$ of the patients in the TRICC study had cardiovascular disease. Although a subgroup analysis from the TRICC study confirmed that a restrictive RBC transfusion strategy generally appears to be safe in most critically ill patients with cardiovascular disease, patients with severe ischemic heart disease were the only subgroup in which the restrictive group had lower (though nonsignificantly) absolute survival than the patients in the liberal group. ${ }^{11}$ We therefore need a similar study in cardiac surgical patients. Multicenter RCTs are expensive and difficult to perform, and they must be carefully designed. ${ }^{201}$ The relative costs of such studies can be justified, however, by the potential economic cost of transfusion-associated morbidity. In 1 analysis, transfusion increased the average cost of a cardiac procedure by as much as $40 \%{ }^{26}$

There is some evidence that the relationship between transfusion and adverse outcome is affected by donor blood processing and storage duration. Prestorage leukodepletion has been reported to reduce transfusion-associated morbidity in meta-analyses of RCTs in cardiac surgery ${ }^{202}$; however, significant heterogeneity in the types of products compared in these trials, as well as in the methods of analysis, have recently called these conclusions into question. ${ }^{203,204}$ In many countries, this issue is no longer relevant because of the introduction of universal leukodepletion as a theoretically motivated strategy for the reduction of prion transmission.

Prolonged RBC storage duration has been shown to increase the frequency of adverse events attributable to transfusion in some reports ${ }^{36}$ but not in others, ${ }^{35,205}$ although there is a strong experimental basis in favor of believing 


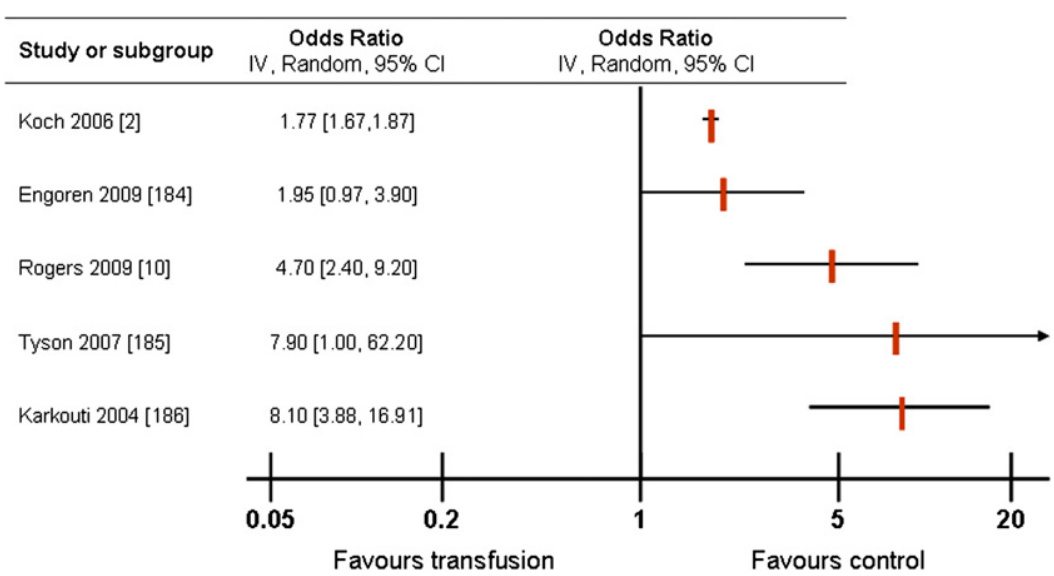

FIGURE 1. Forest plot of studies evaluating the effect of red blood cell transfusion on perioperative mortality (in-hospital or 30-day mortality). IV, Inclusive value; $C I$, confidence interval.

that this may be the case. The "storage lesion" in RBC units is characterized by loss of nitric oxide bioavailability, deformability, and high-energy phosphate depletion in erythrocytes, as well as by accumulation of phospholipids and other toxic species in the supernatant. ${ }^{206}$ Experimental transfusion of stored cells produces more organ injury and tissue hypoxia than does transfusion of fresh RBCs, although the homology between current experimental models and human $\mathrm{RBC}$ transfusion is limited. Reduction of RBC storage limits from 42 days in the United States and 35 days in the United Kingdom is a solution to this issue. ${ }^{207}$ Modification of RBC storage techniques is another. ${ }^{208}$ Prospective trials need to be done, however, to show the improvements achieved by shorter storage limits or modified storage techniques, because adoption of either of the suggested strategies would have significant economic implications.

There is also evidence to suggest that patient-related factors such as age and comorbidity are important

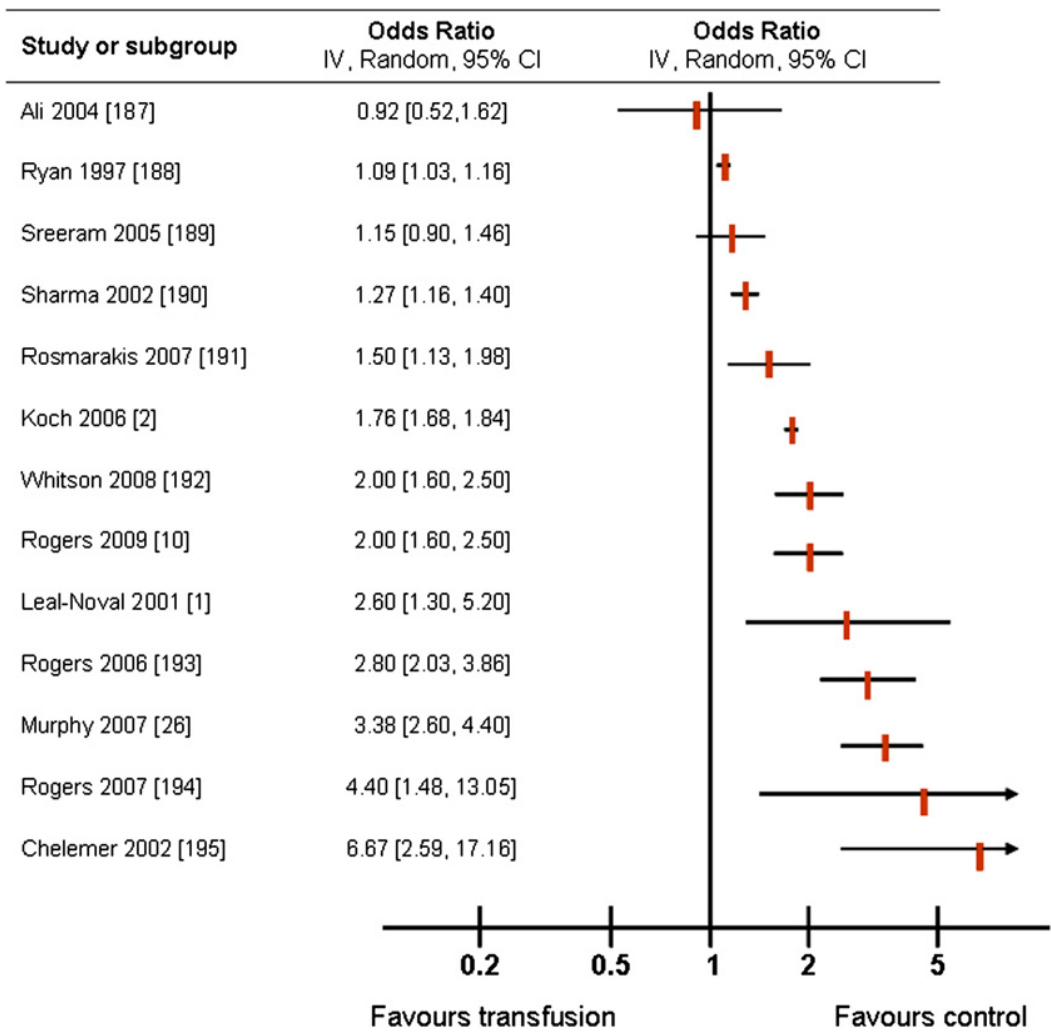

FIGURE 2. Forest plot of studies evaluating the effect of red blood cell transfusion on postoperative infection (sepsis, bacteremia, or any infection). $I V$, Inclusive value; $C I$, confidence interval. 


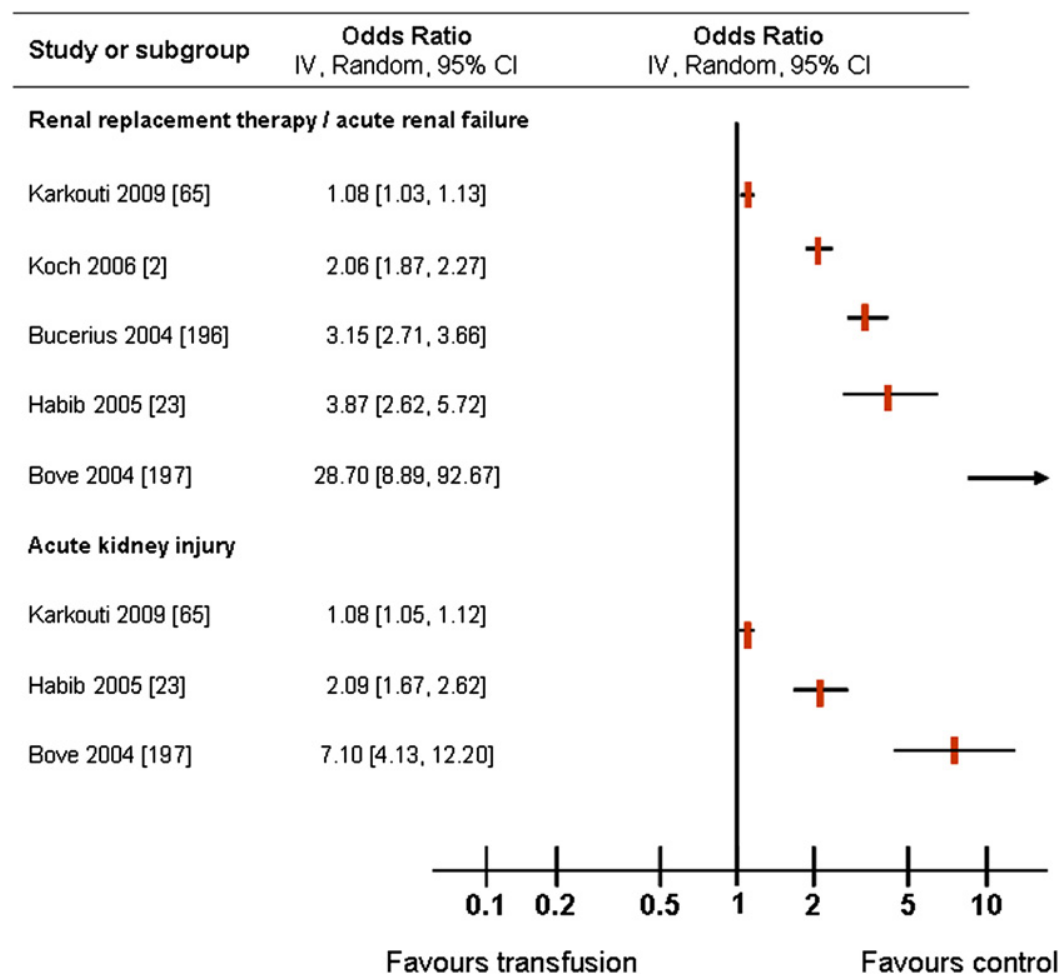

FIGURE 3. Forest plot of studies evaluating the effect of red blood cell transfusion on postoperative acute renal failure or renal replacement therapy and on acute kidney injury. $I V$, Inclusive value; $C I$, confidence interval.

determinants of the effect of transfusion on outcome. This issue is central to clinical transfusion practice. From observational studies, it is apparent that older patients and those with comorbidity are transfused more frequently than are younger, fitter patients. . $2,21,23,26,65,184-193,196-199$ Whether older and sicker patients are more likely to have complications associated with anemia, as opposed to transfusion, is unknown. In the TRICC study, for example, a subgroup analysis demonstrated a significantly higher mortality in the liberal threshold group among younger and less ill patients. ${ }^{200} \mathrm{~A}$ subgroup analysis of retrospective data in cardiac surgery did not support this; the association between transfusion and adverse outcome did not differ between patients of different ages, or in those with greater comorbidity. ${ }^{26}$

Significant gaps in our understanding of the relationship between transfusion and outcome remain. Changing clinical practice or justifying the economic costs of changes in blood processing or storage is unlikely to occur without robust evidence from high-quality RCTs.

Areas of uncertainty and topics for further study. Areas for further study include an assessment of the adverse

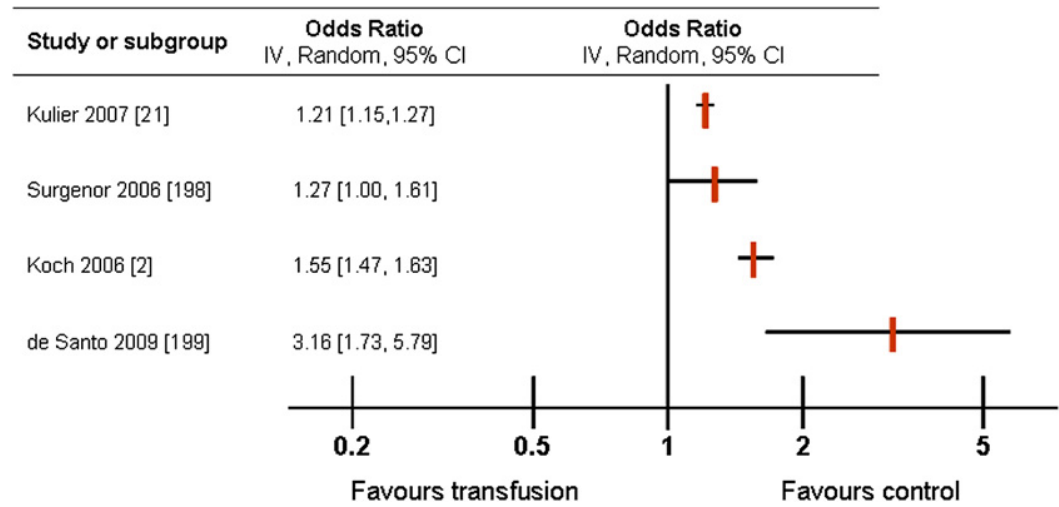

FIGURE 4. Forest plot of studies evaluating the effect of RBC transfusion on postoperative cardiac morbidity (major cardiac complication, low cardiac output). $I V$, Inclusive value; $C I$, confidence interval. 
effects of RBC storage on organ injury. A better understanding of the mechanism by which this occurs might lead to a better definition of indications in which RBC transfusion may be appropriate.

\section{Laboratory and Point-of-Care Tests}

Hemorrhagic diathesis resulting from CPB is a well-known but only partially understood phenomenon. The hemostatic defects that occur are an additive composite of exposure of the blood to an extracorporeal circuit, anticoagulation of the blood with heparin, heparin reversal with protamine, and the dilution and consumption of existing coagulation factors and platelets. To optimize these factors to preserve the hemostatic system, it has been recommended that heparin administration and blood transfusion be guided by rapid-turnaround point-of-care testing. There is no universal heparin dosing scheme or any definitive ACT that confers safety in CPB. Furthermore, although the literature supports point-of-care testing of platelet function to support transfusion algorithms, it is unclear whether the instrument, the behavior, or both, contribute to the reduction in transfusions seen when algorithms are used.

Heparin. The point-of-care methods available for monitoring heparin anticoagulation during CPB include ACT, heparin concentration, heparin management test, and other coagulation tests, such as prothrombinase clotting time and high-dose thrombin time. ${ }^{209}$ When cardiac surgery protocols were first developed, empirical heparin dosing protocols were used, but these soon lost favor to heparin protocols that were based on monitoring the ACT. Heparin activity is determined by the activity of its cofactor antithrombin and other physiologic and environmental variables. Variability of the patient response to heparin and the absence of prospective literature confirming a safe range for ACT values during $\mathrm{CPB}$ are the major impediments to establishing firm guidelines for heparin dosing. Retrospective studies and case reports confirm that there is no magic number for the therapeutic $\mathrm{ACT}$ value and that $\mathrm{CPB}$ can probably be conducted safely with ACT values in the range of 300 seconds and with reduced heparin doses. ${ }^{160}$ If a low ACT strategy is accepted for CPB, however, coated tubing should probably be used. ${ }^{210}$

Conversely, another concept that has received some support in the literature is that the microvascular coagulation that occurs during $\mathrm{CPB}$ is best attenuated by the use of higher doses of heparin. ${ }^{211,212}$ It is possible that the minimum amount of heparin that can be safely used should not be the goal. This idea originated from evidence that ACT values increase on CPB while heparin concentration decreases. The maintenance of a stable heparin concentration during CPB would thus result in the administration of additional doses of heparin, despite a therapeutic ACT. Maintenance of heparin concentration results in higher heparin doses and potentially less activation of the coagulation and fibrinolytic system. The hypothesis that this will result in less bleeding and lower transfusion requirements has been supported in some studies ${ }^{126,213}$ but has been refuted in others. ${ }^{160,214}$ Even in the studies that support heparin concentration-based monitoring and the resultant higher heparin doses that are administered, ${ }^{213}$ however, the reduction in hemostatic activation is not always accompanied by less clinical bleeding.

The ideal technique and therapeutic threshold for ACT monitoring of heparin during $\mathrm{CPB}$ has yet to be established. The initial dose of heparin that is required for an individual patient to achieve a therapeutic ACT for initiation of CPB can be individually tailored and calculated according to an in vitro heparin dose-response curve. These curves can be generated at the point of care and can be used to predict accurately a patient's need for heparin on the basis of sensitivity. Individually tailored heparin and protamine dosing $^{215}$ determined by residual circulating heparin concentration has been successfully studied in cardiac surgery, but evidence is not strong, and such practices have therefore not been universally adopted.

Perioperative bleeding. Attenuation of the inflammatory, coagulation, and fibrinolytic responses to CPB helps to minimize perioperative microvascular bleeding and the need for transfusion of all allogeneic blood products. ${ }^{216}$ It is well documented that these cascades are activated and play a role in end-organ dysfunction associated with CPB. Extracorporeal circulation itself causes consumption of platelets and coagulation factors. Activation of coagulation and fibrinolysis result in platelet count reduction and platelet degranulation during CPB. Fibrinolysis results in the consumption of both coagulation factors and platelets, and inflammation mediates lung injury and other end-organ dysfunction. Interventions aimed at preventing the activation of these cascades are the first-line defense for reducing the bleeding that results from CPB. It has been demonstrated in the literature that tests of platelet function, measured intraoperatively and postoperatively (not preoperatively), correlate best with the occurrence and time course of post-CPB bleeding. Platelet number ${ }^{113,217}$ and bleeding time do not have a strong relationship with perioperative bleeding. ${ }^{218,219}$ Even point-of-care measures of fibrinolysis do not strongly predict postoperative bleeding. ${ }^{220-223}$ The measure of platelet function during the intraoperative or postoperative period is thus critical to devising accurate and appropriate transfusion strategies so that bleeding patients can be treated with only those allogeneic blood products that they actually need. This approach has been confirmed by a small prospective study of thrombelastometry. ${ }^{223}$ Transfusion algorithms that incorporate a test of platelet function have been the most successful in reducing transfusions after cardiac surgery. Open questions include which platelet function tests to use and which other measures should be included in a transfusion algorithm. 
Transfusion algorithms that include thromboelastometry to measure platelet function have proved helpful in reducing transfusion requirements in cardiac surgical patients, as reported in small, prospective studies. ${ }^{78,224-228}$ These algorithms can be further specified to qualify a coagulation defect so that the amount of transfused blood product needed can be predicted by the algorithm. Other viscoelastic tests, ${ }^{229}$ platelet function tests, ${ }^{229-231}$ impedance aggregometry, ${ }^{88}$ and hemostatometry ${ }^{232}$ have been less well studied but have shown benefit for identifying bleeding patients and for directing appropriate treatment. Some of the studies that show a reduction in transfusions demonstrate no significant effect on blood loss. It is therefore unclear whether the transfusion algorithm itself is responsible for the lower transfusion requirements or whether instead the change in behavior represents a bias, causing these studies to show benefit. Depending on the conduct of CPB and the particular hemostatic abnormalities that are expected, some investigations have shown that point-of-care coagulation tests have the strongest correlation with bleeding and should be included early in a transfusion algorithm. ${ }^{233,234}$

The implementation of point-of-care testing requires an investment by any institution that embraces it, but the cost is far outweighed by the benefit if perioperative transfusions are reduced. If patients at highest risk for transfusion could be identified early in the perioperative course, these patients would be the ones who could receive early initiation of point-of-care testing and therefore derive the most benefit. Accurate point-of-care tests to monitor platelet function and other measures of coagulation function are in development. In addition, novel anticoagulation strategies are being investigated that may make the use of heparin during cardiac surgery obsolete. Whether these developments will improve outcomes after cardiac surgery also remains to be determined.

Areas of uncertainty and topics for further study. The current uncertainties that exist in point-of-care monitoring for patients supported on CPB surround heparin monitoring bleeding diagnostics. The optimal dose of heparin to achieve the acceptable ACT for CPB is not yet known. In evaluating bleeding after CPB, dynamic tests of platelet function have helped to rationalize blood transfusion therapy and minimize transfusions in the patient supported on CPB; however, the most accurate hemostasis monitors and tests of platelet function for incorporation into bleeding algorithms have not yet been defined.

\section{Pharmacologic Strategies to Reduce Bleeding}

Apart from the trauma of surgery, bleeding in patients who undergo cardiac surgery may result from impairment of the hemostatic system. The most important mechanisms that contribute to a hemostatic defect include the following: (1) the loss of platelets and impairment of platelet function as a result of CPB, (2) hemodilution with associated decreased plasma concentrations of coagulation factors, (3) incomplete neutralization of heparin given during $\mathrm{CPB},(4)$ an overdose of protamine sulfate (which may itself inhibit coagulation), (5) preoperative use of anticoagulant or antiplatelet drugs, (6) enhanced activity of the fibrinolytic system, in part as a result of circulating plasminogen activators, and (7) low levels of physiologic anticoagulant factors, resulting in ongoing consumption of coagulation factors.

Pharmacologic agents that are capable of promoting hemostasis or fibrin formation or that can block fibrinolytic activity may interfere with the balance between coagulation activation and physiologic anticoagulation. ${ }^{235}$ Although specific correction of these coagulation defects is highly effective and desirable, it is often difficult to achieve because the underlying defect is not always immediately apparent, and many mechanisms may be present simultaneously. Fortunately, there is seldom a strong need to specifically target a factor or pathway in the coagulation or fibrinolytic system that is causally related to the hemostatic defect, because interference in one part of the system may be able to compensate for a defect in another part. Indeed, many clinical studies support the efficacy of prohemostatic interventions in patients undergoing cardiac surgery in terms of reduction in perioperative blood loss and transfusion requirements. The safety of prohemostatic therapy, however, also deserves some consideration. Prohemostatic agents may, at least theoretically, predispose a patient toward thrombotic complications. Here we will briefly review the available clinical evidence on efficacy and safety in cardiac surgery of the 3 types of prohemostatic strategies that have been most intensely investigated: desmopressin, antifibrinolytic agents, and recombinant activated factor VII (rFVIIa). For other prohemostatic interventions, such as prothrombin complex concentrate, fibrinogen concentrate, and factor XIII concentrate, there is no published systematic clinical evidence available for patients undergoing cardiac surgery. These therapies are therefore not discussed here; however, the use of these compounds to reduce bleeding after cardiac surgery is being investigated.

Desmopressin. Desmopressin (1-deamino-8-D-arginine) is a vasopressin analog that, despite minor molecular differences, has retained its antidiuretic properties but has fewer vasoactive effects. ${ }^{236}$ Desmopressin induces release of the contents of the endothelial cell-associated Weibel-Palade bodies, including large multimers of von Willebrand factor, that are relatively active in promoting platelet adhesion to the vessel wall. Indeed, the administration of desmopressin results in a remarkable augmentation of primary hemostasis. In 1986, Salzman and associates ${ }^{237}$ showed that desmopressin $(0.4 \mu \mathrm{g} / \mathrm{kg})$ reduced blood loss and transfusion requirements during complex cardiac surgery by approximately $30 \%$. Subsequent attempts to reproduce these 
findings gave variable results, but most failed to confirm the marked benefit originally described. ${ }^{238,239}$ A few metaanalyses have indicated that although desmopressin helps to reduce perioperative blood loss, the effect is too small to influence other, more clinically relevant outcomes, such as the need for transfusion and reoperation. ${ }^{240-242}$ Studies on desmopressin in cardiac surgery are outdated and were performed in an era when aggressive antiplatelet therapies (thienopyridines) were less common. The role of desmopressin in patients aggressively treated with newgeneration thienopyridines remains to be established.

Antifibrinolytic treatment. Agents that exert antifibrinolytic activity comprise aprotinin and the group of lysine analogs. ${ }^{235,243}$ Aprotinin is a 58-amino acid polypeptide, mainly derived from bovine lung, parotid gland, or pancreas, that directly inhibits the activity of various serine proteases, including plasmin, coagulation factors or inhibitors, and constituents of the kallikrein-kinin and angiotensin system. Lysine analogs such as $\varepsilon$-aminocaproic acid and tranexamic acid are inhibitors of fibrinolysis. ${ }^{243}$ The antifibrinolytic action of lysine analogs is based on the competitive binding of these agents to the lysine-binding sites of a fibrin clot, thereby competing with the binding of plasminogen. Impaired plasminogen binding to fibrin delays the conversion of plasminogen to plasmin and subsequent plasmin-mediated fibrinolysis, which then proceeds at an inefficient and slow rate. Subtle molecular variations among the different lysine analogs may have important consequences for their fibrinolysisinhibiting capacity. Indeed, tranexamic acid is at least 10 times more potent than $\varepsilon$-aminocaproic acid.

The efficacy of antifibrinolytic agents in cardiac surgery has been evaluated in several systematic reviews. ${ }^{241,244-247}$ The Cochrane group ${ }^{247}$ analyzed 211 RCTs with 20,781 participants that were published before July 2006. The vast majority of trials (147 of 211) enrolled patients undergoing cardiac surgery. Ninety-eight studies evaluated aprotinin in 5750 patients randomly allocated to aprotinin and 4394 control patients. RCTs of tranexamic acid and $\varepsilon$-aminocaproic acid were much less numerous: 53 RCTs (3836 patients) investigated tranexamic acid, and only 14 RCTs (801 patients) studied $\varepsilon$-aminocaproic acid. Both aprotinin and tranexamic acid reduced transfusion of allogeneic blood by approximately $30 \%$ and helped to save approximately 1 unit of blood per operation, with a nonstatistically significant trend toward a similar reduction with $\varepsilon$-aminocaproic acid. These figures should be interpreted with caution, however, because of the substantial intercenter variation in blood-saving techniques and transfusion practices, for example because of different transfusion triggers. Importantly, the meta-analyses show that the use of antifibrinolytic agents may result in a 2- to 3-fold reduction in the need for surgical reexploration as a result of bleeding.

The safety of aprotinin was questioned by a study in 4374 patients who underwent elective CABG. ${ }^{248}$ The study was ob- servational and nonrandomized, but it did use a propensity score method to balance the covariates. Compared with untreated control patients, aprotinin (but neither $\varepsilon$-aminocaproic acid nor tranexamic acid) doubled the occurrence of severe renal failure, increased the incidence of myocardial infarction or heart failure by $55 \%$, and was associated with a nearly 2 -fold increase in stroke or other cerebrovascular events. Subsequently, similar results were found in 2 other studies ${ }^{249,250}$ and in an observational survey conducted by the manufacturer in 67,000 patients undergoing cardiac surgery. ${ }^{251}$ A prospective, randomized trial comparing aprotinin and lysine analogs in 2331 high-risk cardiac surgical patients confirmed a higher 30 -day mortality in the aprotinin group (6.0\%), versus $3.9 \%$ in the tranexamic acid group and $4.0 \%$ in the $\varepsilon$-aminocaproic acid group. ${ }^{252}$ On the basis of all these findings, the US Food and Drug Administration suspended the license of aprotinin in the United States, and the manufacturer halted the global distribution of the agent. All in all, tranexamic acid (most frequently used total dose $3-10 \mathrm{~g}$, usually distributed as a loading dose of $2-7 \mathrm{~g}$ and a maintenance dose of $20-250 \mathrm{mg} / \mathrm{h}$ ) is the most appropriate antifibrinolytic agent for use in high risk cardiac surgery. It is not clear from the literature, however, which patients will benefit most from this treatment, what is the most effective dose with the least side effects, ${ }^{253}$ and how to select patients perioperatively who should receive tranexamic acid. Recombinant activated coagulation factor VII. On the basis of the current insight that activation of coagulation in vivo predominantly proceeds by the tissue factor and factor VII pathway, rFVIIa has been developed as a prohemostatic agent and is now available for clinical use $\mathrm{e}^{254}$ and has been licensed for the prevention and treatment of bleeding in patients with antibodies to coagulation factors VIII or IX, so-called inhibitors. In addition, abundant case reports and case series on the hemostatic efficacy of rFVIIa in patients undergoing surgery have been published. ${ }^{255}$ Virtually none of these reports have included adequate controls, however, which makes it very difficult to draw any clinical conclusion. Nevertheless, there is widespread off-label use of rFVIIa for patients with excessive blood loss who have failed conventional treatment. There is limited experience, mostly published as case series or retrospective cohort studies, with rFVIIa in patients undergoing cardiac surgery. ${ }^{256,257} \mathrm{~A}$ small RCT in 20 adult patients undergoing complex noncoronary cardiac surgery requiring $\mathrm{CPB}$ evaluated rFVIIa. ${ }^{258}$ Administration of this agent $(90 \mu \mathrm{g} / \mathrm{kg})$ after discontinuation of bypass and reversal of heparin significantly reduced the need for blood transfusion (relative risk of any transfusion, 0.26 ; 95\% confidence interval, $0.07-$ 0.90). A recent phase II dose-escalation, placebo-controlled study in 172 patients with major blood loss after cardiac surgery showed that the administration of rFVIIa resulted in less blood loss, a significant reduction in the need for reoperation $(25 \%$ in the placebo group, $14 \%$ in the group receiving $\mathrm{rFVIIa}$ at $40 \mu \mathrm{g} / \mathrm{kg}$, and $12 \%$ in the group receiving rFVIIa 
at $80 \mu \mathrm{g} / \mathrm{kg}$ ), and a significantly larger proportion of patients not needing any transfusion (10\% in the placebo group, $28 \%$ in the group receiving $\mathrm{rFVIIa}$ at $40 \mu \mathrm{g} / \mathrm{kg}$, and $32 \%$ in the group receiving rFVIIa at $80 \mu \mathrm{g} / \mathrm{kg}$ ). ${ }^{259}$ More serious adverse events were reported in patients treated with rFVIIa (13\% vs $7 \%$ in the placebo group, difference not significant). Indeed, in view of its prohemostatic activity and potential for thrombotic adverse events, the safety of rFVIIa has been the subject of much attention and surveillance. In clinical RCTs, administration of this agent resulted in a relatively low incidence of thrombotic complications, comparable to that seen among placebo-treated patients ${ }^{254}$; however, most of these studies were performed in patients with impaired coagulation or at low risk for thrombosis. In the trial carried out in patients with a much higher risk, such as those with intracerebral hemorrhage, serious thromboembolic events, mainly myocardial or cerebral infarction, occurred in $7 \%$ of patients treated with rFVIIa compared with $2 \%$ of placebo-treated patients. There is thus some indication that rFVIIa may increase the risk of thrombotic complications, and this needs to be balanced with its potential benefit in patients with severe blood loss. More RCTs are needed to establish efficacy and safety in patients undergoing cardiac surgery. ${ }^{260}$

Areas of uncertainty and topics for further study. Because the window between benefit and risk of various prohemostatic options is relatively small, it is important, aside from the specific properties of the various interventions, to look critically to patient selection for this type of treatment. Prohemostatic agents may provide a relatively large benefit for patients undergoing surgery that carries a high risk of bleeding (reoperative surgery, combined procedures, and so on). In less complex cases, the prohemostatic benefit may be annihilated by the side effects of the intervention. Apart from retrospective subgroup analyses, however, there has been surprisingly little study on which procedures may be best suited for the concomitant use of prohemostatic strategies. Apart from the surgical intervention, patient factors may also affect the expected benefitharm balance for prohemostatic interventions, and here even less is known. Future prospective studies could focus on identifying patient criteria and situations that warrant the use of prohemostatic interventions.

A further issue is the lack of properly validated monitoring tools to guide prohemostatic interventions in patients undergoing cardiac surgery. Dosing of prohemostatic drugs may therefore be problematic, and it is likely that the "one size fits all" strategy that is now generally adopted results in marked underdosing or overdosing of individual patients. Future studies should aim to develop and validate properly monitoring systems to properly dose individual patients during and after cardiac surgery.

Another area for further research is the efficacy and safety of alternative prohemostatic interventions. Coagulation factor concentrates, including fibrinogen concentrate, FXIII, and rFVIIa, have a marked effect on laboratory parameters of coagulation, but it is not clear how this translates into a beneficial effect on clinically relevant outcomes. In addition, the safety of these interventions has been studied only marginally in patients undergoing cardiac surgery. ${ }^{261,262}$

\section{Patient Blood Management Policy}

The current magnitude of transfusion costs. According to the US blood collection and utilization survey for 2006 , the product cost for RBCs was $\$ 3.2$ billion. ${ }^{6}$ This, however, represents only a part of the overall financial burden of transfusion. In addition to product cost, there are many other cost elements involved, and attempts have been made to determine those by means of process flow analyses. ${ }^{263,264}$ The panelists of the first multidisciplinary Cost of Blood Consensus Conference recognized the limitations of this methodology and proposed that the next iteration to determine the totality of transfusion-related costs would be process cost analysis, also known as activitybased costing. ${ }^{265}$ Subsequently, this methodology was applied in the surgical setting at 4 centers. In the 2 US hospitals, the total costs per unit transfused were $\$ 726$ and $\$ 1183$, representing 3.2 to 4.8 times the acquisition cost for RBCs. ${ }^{266}$ As determined from the $\$ 3.2$ billion cost volume for RBCs and the lower bound ratio of 1:3.2, the extrapolated RBC transfusion-related direct cost for US health care providers could be $\$ 10.2$ billion, with an upper bound of $\$ 15.4$ billion. This figure, however, does not include elements that contribute to the total societal cost of blood, including donor costs, hemovigilance, lost productivity, and midterm to long-term adverse transfusion outcomes. ${ }^{267}$ Even without considering these additional factors, the cost of RBC transfusions represents a major economic dimension. Activitybased cost studies for plasma and platelet transfusions are still needed for a more complete picture.

The future magnitude of transfusion costs. The widening gap between supply and demand for allogeneic blood components is expected to escalate the cost of transfusion. The supply side is increasingly under pressure in response a changing ratio between the donating and the nondonating population. To measure the effect of this shift, a socioeconomic metric called old age dependency ratio can be applied in a slightly altered form. It divides the nonworking population aged 65 years by the working population aged 15 to 64 years, multiplied by 100 . The 2005 old age dependency ratio for 25 European Union countries was 24.8, meaning that a mean of 24.8 elderly persons depended on 100 working individuals. In the past 20 years, the ratio in the EU has risen from approximately 20 to 25 . According to migration trends and birth and death rates in high human development index countries, it will climb to almost 40 during the next 20 years. ${ }^{268}$ With slight changes, this metric has been introduced as a total transfusion dependency ratio (Equation 1), relating the non-blood-donating population of individuals 
aged 0 to 17 years and 65 years and older to the donating population of individuals aged 18 to 64 years $^{268}$ :

$$
T T D R=\frac{P_{N D}}{P_{D}} \times 100
$$

where $P_{N D}$ is the non-blood-donating (dependent) population, aged 0 to 17 years plus 65 years and older, and $P_{D}$ is the blood-donating population, aged 18 to 64 years.

If current donation patterns continue, TTDR in developed countries will more or less double during the next 20 years. Moreover, a recent Canadian study showed that the most generous segment of blood donors (15-24 years of age) is shrinking in both absolute and relative terms. ${ }^{269}$

The problem on the demand side is even more challenging. Wells and colleagues ${ }^{270}$ showed that most blood is used in treatment of the older age segments of the population. Because older patients are by far the fastest growing group, this demographic trend has a leveraging effect on blood use. An analysis in Western Australia showed that patients 70 years old and older received 179.6 RBC units per 1000 population, compared with 33.5 in the 40- to 69-year age segment and only 10.7 in the 0 - to 39 -year age segment. The use of RBC units in the segment of patients at least 70 years old accounted for more than $45 \%$ of all RBCs transfused. ${ }^{271}$ If current donation and transfusion behavior prevails, blood shortage will therefore become chronic, and, following the law of supply and demand, component cost will rise sharply. Model calculations have yet to be performed.

Problems with health economic analyses comparing transfusion with patient blood management modalities. The burden of current and future transfusion cost necessitates comparative evaluations of other hemotherapeutic options: patient blood management modalities such as ANH, intraoperative cell salvage, anemia management with erythropoietin-stimulating agents or iron, bleeding management with various hemostatic agents, point-of-care diagnostics, and others. The appropriate health policy decision-making tool would be the incremental costeffectiveness ratio (ICER; Equation 2), defined as the change in costs $(C)$ of a therapeutic intervention (relative to the best available alternative treatment or to doing nothing) relative to the change in effects $(E)$. The effect is expressed in outcome measures such as life years gained, quality-adjusted life years gained, the number of deaths prevented, the number of infections prevented, the number of symptom-free days, or other parameters. For the comparison of standard transfusion with patient blood management, the equation to calculate the ICER is as follows:

$$
I C E R=\frac{C_{P B M X}-C_{T x n}}{E_{P B M X}-E_{T x n}}
$$

where $C_{T x n}$ is the average total cost in the transfusion cohort, $C_{P B M X}$ is the average total cost in a cohort treated with patient blood management modality $X, E_{T x n}$ is the total effectiveness in the transfusion cohort, and $E_{P B M X}$ is the total effectiveness in the cohort treated with patient blood management modality $X$.

Unlike in other fields of pharmacoeconomics, the literature shows a paucity of evidence to determine both the costs and the effects of most, if not all, patient blood management modalities. Some studies have investigated the cost-effectiveness of ANH versus allogeneic RBC transfusions, but none have been based on process cost analyses. Others have compared autologous with allogeneic RBC transfusions or leukodepleted with nonleukodepleted RBC transfusions but have not compared patient blood management modalities. Most importantly, there is little evidence for a positive effect of RBC transfusion with the exception of extreme or acute bleeding settings. ${ }^{29}$ On the contrary, a large number of observational studies have shown transfusion to be independently associated in a dose-dependent manner with increased mortality and morbidity, including nosocomial infection, sepsis, pneumonia, ischemic events, acute respiratory distress syndrome, acute lung injury, and multiorgan failure, along with increased ICU admission and lengthened ICU and hospital stays. ${ }^{10,25,26,272-278}$ Only high-powered RCTs or the systematic application of the Bradford-Hill criteria for assessing evidence of causation ${ }^{279}$ will yield sufficient evidence to determine whether transfusion is a cause of these adverse outcomes. If the relation is causal, the overall costs of transfusion will significantly exceed current calculations.

Results of patient blood management programs. Although evidence is still lacking to determine the costeffectiveness of specific patient blood management modalities, clinicians and hospital administrators should not ignore the fact that patient blood management programs have resulted in savings in terms of avoided allogeneic RBC transfusions and in general have been cost-effective. ${ }^{280,281}$ Blood conservation programs in the 1990s showed significant reductions in blood use with improved outcomes. ${ }^{280}$ Englewood Hospital and Medical Center in New Jersey reported a $42 \%$ reduction in blood use during the first 4 years of their program. Since its inception, the cardiac surgery program at this center has used a broad-based blood conservation program for all patients who are admitted for cardiac surgery. ${ }^{281}$ In this single-center study, an overall transfusion rate of $13 \%$ among patients undergoing CABG, valve operations, and CABG with valve operations was reported. Furthermore, these achievements have been maintained without any increase in morbidity and mortality when stratifying patients undergoing isolated CABG surgery. ${ }^{271,281,282}$ Other centers have also reported findings of reductions in transfusions for patients undergoing cardiac surgery, with lower costs for blood product acquisition and substantial savings related to shortened stay and lower incidences of 
TABLE 2. Factors discussed here for which further research may provide a higher level of evidence for clinical practice in cardiac surgery

\begin{tabular}{|c|c|}
\hline Factor & Limitations of current evidence \\
\hline \multirow[t]{3}{*}{ Acute normovolemic hemodilution } & $\begin{array}{l}\text { Temporal effect of storage on oxygen-carrying } \\
\text { capacity of blood products unclear }\end{array}$ \\
\hline & Data lacking on patient subpopulations \\
\hline & Data lacking on patient subpopulations \\
\hline \multirow[t]{2}{*}{ Acute platelet pheresis } & Methodology not standardized \\
\hline & Lack of evidence in patient subpopulations \\
\hline Adverse outcomes & $\begin{array}{l}\text { All available clinical evidence is associative not } \\
\text { causal }\end{array}$ \\
\hline Anticoagulation & $\begin{array}{l}\text { Limited data on the effectiveness of alternative } \\
\text { anticoagulants }\end{array}$ \\
\hline Anticoagulation measurement & Optimal measure and threshold unclear \\
\hline
\end{tabular}

Anticoagulation measurement

Biocompatible CPB circuits

Closed vs open circuits

Extreme-risk patients

Hemoglobin

High-risk groups

Indicators and discriminators of effectiveness

Mini-CPB

Platelet function testing
Lack of data on the significance of antithrombotic activity in anticoagulation

Lack of data on the significance of endogenous endothelium-derived factor activity in anticoagulation

Unclear whether inadequate ACT response to heparin reflects inadequate anticoagulation

Data lacking on newer (nonheparin or multimolecular) coatings

No evidence that closed circuits alone reduce transfusion rate

Population poorly defined

Poor evidence for relationship among transfusion, hemoglobin, and tissue oxygenation

Unknown differences in quality of endogenous vs exogenous hemoglobin

Temporal variability of hemoglobin is not well characterized

All available clinical evidence is associative, not causal

Insufficient evidence

Too few patients and single components compared in existing randomized, controlled trials

No randomized data available

Optimal device unclear

Appropriate acceptable values to determine optimal pre-surgical platelet inhibition level not welldefined
Issues for future research

Does short-term storage of blood products affect effectiveness?

What are the appropriate hemodilution targets in different patient subpopulations?

What are the benefits of acute normovolemic hemodilution in different patient subpopulations?

Does higher platelet yield correlate with effectiveness?

Do antiplatelet agents affect the quality of the product?

Does transfusion cause adverse outcomes?

Are alternative anticoagulation agents safer and more effective than heparin?

Which is the optimal method with which to monitor anticoagulation?

What are the minimum acceptable target threshold levels?

Should antithrombotic activity be measured preoperatively?

Does antithrombotic activity correlate with outcome?

Should the activity of other endogenous endothelium-derived factors be measured?

Should low ACT activity be supplemented in heparin-exposed patients?

Do coatings other than heparin offer any additional benefit?

Does separation of cardiotomy shed blood decrease blood activation, bleeding, and transfusion rate?

Is patient blood management strategy different in extreme-risk patients?

Which other markers for transfusion might supplement hemoglobin?

Does transfusion improve tissue oxygenation?

What is the oxygen-carrying capacity of hemoglobin ex vivo?

What is the clinical impact of temporal changes in hemoglobin?

Does the relationship between transfusion and adverse outcomes vary in different patient subpopulations?

Are there easily-measurable objective indicators or discriminators of patient subpopulations that may benefit from transfusion?

Does the use of a comprehensive strategy result in fewer transfusions?

Can randomized clinical trials provide higher-level data?

Can technologic improvements be validated?

Which range of platelet inhibition minimizes thromboembolic/hemorrhagic risk? 
TABLE 2. Continued

\begin{tabular}{|c|c|c|}
\hline Factor & Limitations of current evidence & Issues for future research \\
\hline & $\begin{array}{l}\text { Appropriate point-of-care methodology to determine } \\
\text { the degree of platelet inhibition unclear }\end{array}$ & $\begin{array}{l}\text { Which platelet function test is most useful to } \\
\text { determine platelet inhibition? }\end{array}$ \\
\hline Point-of-care testing & $\begin{array}{l}\text { Appropriate point-of-care methodology for testing to } \\
\text { guide treatment of the bleeding patient unclear }\end{array}$ & $\begin{array}{l}\text { Which tests of heparin neutralization and hemostasis } \\
\text { are optimal for use in an algorithm for the bleeding } \\
\text { patient? }\end{array}$ \\
\hline \multirow[t]{2}{*}{ Preoperative donation } & $\begin{array}{l}\text { Lack of sufficient data to change clinical practice; } \\
\text { benefit vs allogeneic blood products unclear }\end{array}$ & What are the benefits of autologous donation? \\
\hline & & Is autologous donation cost-effective? \\
\hline Presurgical management & $\begin{array}{l}\text { Timing of surgery in patients receiving dual } \\
\text { antiplatelet therapy not well characterized }\end{array}$ & $\begin{array}{l}\text { Does platelet function testing minimize transfusion } \\
\text { in patients treated with anti-platelet agents? } \\
\text { Is the transfusion rate dependent on the timing of } \\
\text { antiplatelet therapy withdrawal before surgery? }\end{array}$ \\
\hline Reduced hemodilution during $\mathrm{CPB}$ & $\begin{array}{l}\text { Lack of data related to temporal exposure to low } \\
\text { hemoglobin }\end{array}$ & $\begin{array}{l}\text { Is less perioperative variation in hemoglobin } \\
\text { associated with a lower transfusion rate? } \\
\text { Is the time of exposure to a low hemoglobin more } \\
\text { important than nadir hemoglobin? }\end{array}$ \\
\hline Reduced systemic heparinization & $\begin{array}{l}\text { Heparin dose and target ACT not clearly defined; } \\
\text { lack of high-level evidence }\end{array}$ & $\begin{array}{l}\text { Does reduction of systemic heparinization in the } \\
\text { setting of biocompatible circuits decrease bleeding } \\
\text { and transfusion rate? }\end{array}$ \\
\hline \multirow[t]{2}{*}{$\mathrm{rSO}_{2}$} & $\begin{array}{l}\text { Qualitative marker of regional tissue oxygenation; } \\
\text { unclear correlation with global oxygenation; } \\
\text { normal values and methodology not well defined }\end{array}$ & $\begin{array}{l}\text { Is } \mathrm{rSo}_{2} \text { useful in the transfusion decision-making } \\
\text { process? }\end{array}$ \\
\hline & May be increased by blood transfusion & Is $\mathrm{rSO}_{2}$ useful as (part of) a transfusion trigger? \\
\hline $\mathrm{ScvO}_{2} \mathrm{SvO}_{2}$ & $\begin{array}{l}\text { Clinical data limited; animal data may not be } \\
\text { transferable to human patients }\end{array}$ & $\begin{array}{l}\text { Is } \mathrm{ScvO}_{2} \text { or } \mathrm{SvO}_{2} \text { superior to hemoglobin as a trigger } \\
\text { for transfusion? }\end{array}$ \\
\hline \multirow[t]{3}{*}{ Shed blood processing } & $\begin{array}{l}\text { Unclear whether washing cardiotomy shed blood } \\
\text { results in loss of platelets and coagulation factors }\end{array}$ & $\begin{array}{l}\text { What is the amount of blood that can be safely } \\
\text { processed? }\end{array}$ \\
\hline & & $\begin{array}{l}\text { Which shed blood processing method is most } \\
\text { effective? }\end{array}$ \\
\hline & & Is shed blood processing cost-effective? \\
\hline Storage duration & $\begin{array}{l}\text { All available clinical evidence is associative, not } \\
\text { causal }\end{array}$ & $\begin{array}{l}\text { Is storage time a factor in the relationship between } \\
\text { transfusion and adverse outcomes? }\end{array}$ \\
\hline Timing of surgery & Only small, single-center trials have been reported & $\begin{array}{l}\text { Can prospective, randomized multicenter trials } \\
\text { provide higher-level data? }\end{array}$ \\
\hline Transfusion trigger & No validated physiologic transfusion triggers & $\begin{array}{l}\text { Could a physiologic transfusion trigger replace } \\
\text { a static (hemoglobin) trigger? }\end{array}$ \\
\hline
\end{tabular}

$\overline{A C T}$, Activated clotting time; $\mathrm{CPB}$, cardiopulmonary bypass; $r \mathrm{SO}_{2}$, regional cortical oxygen saturation; $\mathrm{Scvo}_{2}$, central venous oxygen saturation; $\mathrm{SvO}_{2}$, mixed venous oxygen saturation.

complications. $^{280,283-285}$ It is therefore essential to produce sufficient evidence for cost-effectiveness analyses across all major patient blood management modalities to identify those with the most impact.

Areas of uncertainty and topics for further study. The cost of RBC transfusion from a health care provider's perspective is higher than previously assumed. The intended effects of transfusion, apart from hemoglobin rise, in most patient populations have not been satisfactorily demonstrated. Conversely, a number of observational studies show that many unintended or negative outcomes are associated with transfusion. The cost-effectiveness of RBC transfusion is therefore unclear. Patient blood management programs have been demonstrated to be cost-effective overall, but it is unclear to what degree specific patient blood management modalities have contributed to the effective- ness. More evidence is necessary for meaningful ICERs, allowing optimal resource allocation.

\section{Concluding Remarks}

The aim of this article has been to evaluate existing published evidence related to patient blood management in cardiac surgical patients to generate an inventory or "wish list" of areas that urgently require further research before truly evidence-based recommendations to optimize patient care can be made. The primary areas in which further research is required and suggested issues to be addressed are summarized in Table 2. The IIHMCS author group believes that the following issues should be given the highest priority:

- Although hemoglobin levels are currently used as the standard measure of organ dysoxia, hemoglobin may be an 
inadequate trigger for transfusion. In the very low range, measured hemoglobin levels may be helpful in guiding patient management; in the range typically seen in cardiac surgery clinical practice, however, we suggest that other physiologic markers may usefully supplement hemoglobin.

- It is currently unclear whether limiting excessive hemodilution during CPB thereby limits transfusion needs, and controlled studies in this area are warranted.

- The impact of patient comorbidity, the age of stored RBCs, and the presence of a regional oxygen supply dependency on patient outcomes as a result of transfusion is unclear and requires further study.

- Elucidation of the role of closed versus open CPB circuits and larger studies on mini-CPB are needed.

- The optimal dose and monitoring of heparinization and heparin reversal remain to be established.

- Further research is needed into the use of both current and new antifibrinolytics and anticoagulants.

- The appropriate application of fresh-frozen plasma and platelet transfusions.

- In patients who receive preoperative antiplatelet agents, specific point-of-care platelet function tests should be explored for their capacity to detect patients at high risk for postoperative bleeding and transfusion.

- Prohemostatic agents may provide the most benefit in patients at highest risk of bleeding; however, little is known about which procedures and patient subgroups might benefit most from prohemostatic interventions. Properly validated monitoring tools to guide prohemostatic interventions are also needed.

- Some patient subpopulations are at exceptional risk for receiving blood products and experiencing poor outcomes, and they require careful monitoring and management; however, few data to date support management decisions in these small patient groups.

- An assessment of the cost-effectiveness of ANH in different patient populations is also needed.

- We suggest that a rigorous cost analysis be undertaken to evaluate the optimal period between cessation of anticoagulation therapy and surgery.

- The cost of RBC transfusion is high, and the costeffectiveness unclear. Some patient blood management programs have demonstrated cost-effectiveness, but the contributing modalities are unclear and require further investigation.

- Physician education is needed to ensure adherence to clinical practice guidelines.

The creation of the term patient blood management reflects a paradigm shift from blood transfusion to blood management policies that incorporate multimodal blood conservation strategies. To optimize these strategies in cardiac surgery, further data are required in many areas. Some of these data will best be generated in the context of clinical
RCTs. Other questions may best be answered by expanding or modifying existing database fields to collect data on, for example, specific patient subpopulations and long-term outcomes. We therefore encourage researchers, professional societies, funding agencies, and industrial partners to focus their attention on the areas that we have highlighted here. With the support of a more solid evidence base, we hope that future management guidelines can not only be adapted to reflect new insights into optimal patient management but also universally adopted into clinical practice.

\section{References}

1. Leal-Noval SR, Rincón-Ferrari MD, García-Curiel A, Herruzo-Avilés A, Camacho-Laraña P, Garnacho-Montero J, et al. Transfusion of blood components and postoperative infection in patients undergoing cardiac surgery. Chest. 2001; 119:1461-8.

2. Koch CG, Li L, Duncan AI, Mihaljevic T, Cosgrove DM, Loop FD, et al. Morbidity and mortality risk associated with red blood cell and blood-component transfusion in isolated coronary artery bypass grafting. Crit Care Med. 2006; 34:1608-16.

3. Koch CG, Li L, Duncan AI, Mihaljevic T, Loop FD, Starr NJ, et al. Transfusion in coronary artery bypass grafting is associated with reduced long-term survival. Ann Thorac Surg. 2006;81:1650-7.

4. Engoren MC, Habib RH, Zacharias A, Schwann TA, Riordan CJ, Durham SJ. Effect of blood transfusion on long-term survival after cardiac operation. Ann Thorac Surg. 2002;74:1180-6.

5. Shehata N, Wilson K, Mazer CD, Tomlinson G, Streiner D, Hebert P, et al Factors affecting perioperative transfusion decisions in patients with coronary artery disease undergoing coronary artery bypass surgery. Anesthesiology. 2006;105:19-27.

6. Sihler KC, Napolitano LM. Complications of massive transfusion. Chest. 2010;137:209-20. Erratum in: Chest. 2010;137:744.

7. Raghavan M, Marik PE. Anemia, allogenic blood transfusion, and immunomodulation in the critically ill. Chest. 2005;127:295-307.

8. Ferraris VA, Ferraris SP, Saha SP, Hessel EA 2nd, Haan CK, et al., Society of Thoracic Surgeons Blood Conservation Guideline Task Force. Perioperative blood transfusion and blood conservation in cardiac surgery: the Society of Thoracic Surgeons and The Society of Cardiovascular Anesthesiologists clinical practice guideline. Ann Thorac Surg. 2007;83(5 Suppl): S27-86.

9. Likosky DS, FitzGerald DC, Groom RC, Jones DK, Baker RA, Shann KG et al. Effect of the perioperative blood transfusion and blood conservation in cardiac surgery Clinical Practice Guidelines of the Society of Thoracic Surgeons and the Society Of Cardiovascular Anesthesiologists upon clinical practices. J Extra Corpor Technol. 2010;42:114-21.

10. Rogers MA, Blumberg N, Saint S, Langa KM, Nallamothu BK. Hospital variation in transfusion and infection after cardiac surgery: a cohort study. BMC Med. 2009;7:37.

11. Hébert PC, Yetisir E, Martin C, Blajchman MA, Wells G, Marshall J, et al. Is a low transfusion threshold safe in critically ill patients with cardiovascular diseases? Crit Care Med. 2001;29:227-34

12. Freudenberger RS, Carson JL. Is there an optimal hemoglobin value in the cardiac intensive care unit? Curr Opin Crit Care. 2003;9:356-61.

13. Practice Guidelines for blood component therapy: A report by the American Society of Anesthesiologists Task Force on Blood Component Therapy. Anesthe siology. 1996;84:732-47.

14. van Bommel J, de Korte D, Lind A, Siegemund M, Trouwborst A, Verhoeven AJ, et al. The effect of the transfusion of stored RBCs on intestinal microvascular oxygenation in the rat. Transfusion. 2001;41:1515-23.

15. Tsai AG, Cabrales P, Intaglietta M. Microvascular perfusion upon exchange transfusion with stored red blood cells in normovolemic anemic conditions. Transfusion. 2004;44:1626-34

16. Stover EP, Siegel LC, Parks R, Levin J, Body SC, Maddi R, et al. Variability in transfusion practice for coronary artery bypass surgery persists despite national consensus guidelines: A 24-institution study. Institutions of the Multicenter Study of Perioperative Ischemia Research Group. Anesthesiology. 1998;88: 327-33. 
17. Ott E, Mazer CD, Tudor IC, Shore-Lesserson L, Snyder-Ramos SA, Finegan BA, et al. Coronary artery bypass graft surgery-care globalization: the impact of national care on fatal and nonfatal outcome. J Thorac Cardiovasc Surg. 2007;133:1242-51.

18. Gombotz H, Rehak PH, Shander A, Hofmann A. Blood use in elective surgery: the Austrian benchmark study. Transfusion. 2007;47:1468-80.

19. Snyder-Ramos SA, Möhnle P, Weng YS, Böttiger BW, Kulier A, Levin J, et al. The ongoing variability in blood transfusion practices in cardiac surgery. Transfusion. 2008;48:1284-99.

20. Ranucci M, Romitti F, Isgrò G, Cotza M, Brozzi S, Boncilli A, et al. Oxygen delivery during cardiopulmonary bypass and acute renal failure after coronary operations. Ann Thorac Surg. 2005;80:2213-20.

21. Kulier A, Levin J, Moser R, Rumpold-Seitlinger G, Tudor IC, SnyderRamos SA, et al. Impact of preoperative anemia on outcome in patients undergoing coronary artery bypass graft surgery. Circulation. 2007;116:471-9.

22. Murphy GJ, Angelini GD. Indications for blood transfusion in cardiac surgery. Ann Thorac Surg. 2006;82:2323-34.

23. Habib RH, Zacharias A, Schwann TA, Riordan CJ, Engoren M, Durham SJ, et al. Role of hemodilutional anemia and transfusion during cardiopulmonary bypass in renal injury after coronary revascularization: implications on operative outcome. Crit Care Med. 2005;33:1749-56.

24. Spiess BD, Ley C, Body SC, Siegel LC, Stover EP, Maddi R, et al. Hematocrit value on intensive care unit entry influences the frequency of Q-wave myocardial infarction after coronary artery bypass grafting. The Institutions of the Multicenter Study of Perioperative Ischemia (McSPI) Research Group. J Thorac Cardiovasc Surg. 1998;116:460-7.

25. Marik PE, Corwin HL. Efficacy of red blood cell transfusion in the critically ill: a systematic review of the literature. Crit Care Med. 2008;36:2667-74.

26. Murphy GJ, Reeves BC, Rogers CA, Rizvi SI, Culliford L, Angelini GD. Increased mortality, postoperative morbidity, and cost after red blood cell transfusion in patients having cardiac surgery. Circulation. 2007;116:2544-52.

27. Spahn DR, Madjdpour C. Physiologic transfusion triggers: do we have to use (our) brain? Anesthesiology. 2006;104:905-6.

28. Madjdpour C, Spahn DR, Weiskopf RB. Anemia and perioperative red blood cell transfusion: a matter of tolerance. Crit Care Med. 2006;34(5 Suppl):S102-8.

29. Vincent JL, Sakr Y, De Backer D, Van der Linden P. Efficacy of allogeneic red blood cell transfusions. Best Pract Res Clin Anaesthesiol. 2007;21:209-19.

30. Gonzalez AM, Yazici I, Kusza K, Siemionow M. Effects of fresh versus banked blood transfusions on microcirculatory hemodynamics and tissue oxygenation in the rat cremaster model. Surgery. 2007;141:630-9.

31. Cabrales P. Effects of erythrocyte flexibility on microvascular perfusion and oxygenation during acute anemia. Am J Physiol Heart Circ Physiol. 2007;293: H1206-15.

32. Cabrales P, Tsai AG, Intaglietta M. Modulation of perfusion and oxygenation by red blood cell oxygen affinity during acute anemia. Am J Respir Cell Mol Biol. 2008;38:354-61.

33. Sakr Y, Chierego M, Piagnerelli M, Verdant C, Dubois MJ, Koch M, et al. Microvascular response to red blood cell transfusion in patients with severe sepsis. Crit Care Med. 2007;35:1639-44.

34. Vamvakas EC, Carven JH. Length of storage of transfused red cells and postoperative morbidity in patients undergoing coronary artery bypass graft surgery. Transfusion. 2000;40:101-9.

35. van de Watering L, Lorinser J, Versteegh M, Westendord R, Brand A. Effects of storage time of red blood cell transfusions on the prognosis of coronary artery bypass graft patients. Transfusion. 2006;46:1712-8.

36. Koch CG, Li L, Sessler DI, Figueroa P, Hoeltge GA, Mihaljevic T, et al. Duration of red-cell storage and complications after cardiac surgery. $N$ Engl J Med. 2008;358:1229-39.

37. Kapoor PM, Kakani M, Chowdhury U, Choudhury M, Lakshmy, Kiran U. Early goal-directed therapy in moderate to high-risk cardiac surgery patients. Ann Card Anaesth. 2008;11:27-34.

38. Kirkeby-Garstad I, Sellevold OF, Stenseth R, Skogvoll E. Mixed venous oxygen desaturation during early mobilization after coronary artery bypass surgery. Acta Anaesthesiol Scand. 2005;49:827-34.

39. Heiselman D, Jones J, Cannon L. Continuous monitoring of mixed venous oxygen saturation in septic shock. J Clin Monit. 1986;2:237-45.

40. Scheinman MM, Brown MA, Rapaport E. Critical assessment of use of central venous oxygen saturation as a mirror of mixed venous oxygen in severely ill cardiac patients. Circulation. 1969;40:165-72.

41. Dueck MH, Klimek M, Appenrodt S, Weigand C, Boerner U. Trends but not individual values of central venous oxygen saturation agree with mixed venous oxygen saturation during varying hemodynamic conditions. Anesthesiology. 2005; 103:249-57.

42. Sander M, Spies CD, Foer A, Weymann L, Braun J, Volk T, et al. Agreement of central venous saturation and mixed venous saturation in cardiac surgery patients. Intensive Care Med. 2007;33:1719-25.

43. Chawla LS, Zia H, Gutierrez G, Katz NM, Seneff MG, Shah M. Lack of equivalence between central and mixed venous oxygen saturation. Chest. 2004;126: 1891-6.

44. Vincent JL. Does central venous oxygen saturation accurately reflect mixed venous oxygen saturation? Nothing is simple, unfortunately. Intensive Care Med. 1992;18:386-7.

45. Shann KG, Likosky DS, Murkin JM, Baker RA, Baribeau YR, DeFoe GR, et al. An evidence-based review of the practice of cardiopulmonary bypass in adults: a focus on neurologic injury, glycemic control, hemodilution, and the inflammatory response. J Thorac Cardiovasc Surg. 2006;132:283-90.

46. Murkin JM. Applied neuromonitoring and improving CNS outcomes. Semin Cardiothorac Vasc Anesth. 2005;9:139-42.

47. Yao FS, Tseng CC, Ho CY, Levin SK, Illner P. Cerebral oxygen desaturation is associated with early postoperative neuropsychological dysfunction in patients undergoing cardiac surgery. J Cardiothorac Vasc Anesth. 2004;18:552-8.

48. Slater JP, Guarino T, Stack J, Vinod K, Bustami RT, Brown JM 3rd, et al. Cerebral oxygen desaturation predicts cognitive decline and longer hospital stay after cardiac surgery. Ann Thorac Surg. 2009;87:36-45.

49. Murkin JM. Perioperative multimodality neuromonitoring: an overview. Semin Cardiothorac Vasc Anesth. 2004;8:167-71.

50. Goldman S, Sutter F, Ferdinand F, Trace C. Optimizing intraoperative cerebral oxygen delivery using noninvasive cerebral oximetry decreases the incidence of stroke for cardiac surgical patients. Heart Surg Forum. 2004;7:E376-81.

51. Edmonds HL Jr, Rodriguez RA, Audenaert SM, Austin EH 3rd, Pollock SB Jr, Ganzel BL. The role of neuromonitoring in cardiovascular surgery. J Cardiothorac Vasc Anesth. 1996;10:15-23.

52. Jensen G, Nielsen HB, Ide K, Madsen PL, Svendsen LB, Svendsen UG, et al. Cerebral oxygenation during exercise in patients with terminal lung disease. Chest. 2002;122:445-50.

53. Nielsen HB, Boushel R, Madsen P, Secher NH. Cerebral desaturation during exercise reversed by $\mathrm{O}_{2}$ supplementation. Am J Physiol. 1999;277(3 Pt 2): H1045-52.

54. Murkin JM, Adams SJ, Novick RJ, Quantz M, Bainbridge D, Iglesias I, et al. Monitoring brain oxygen saturation during coronary bypass surgery: a randomized, prospective study. Anesth Analg. 2007;104:51-8.

55. Torella F, Haynes SL, McCollum CN. Cerebral and peripheral oxygen saturation during red cell transfusion. J Surg Res. 2003;110:217-21.

56. Weiskopf RB, Kramer JH, Viele M, Neumann M, Feiner JR, Watson JJ, et al. Acute severe isovolemic anemia impairs cognitive function and memory in humans. Anesthesiology. 2000;92:1646-52

57. Weiskopf RB, Feiner J, Hopf HW, Viele MK, Watson JJ, Kramer JH, et al. Oxygen reverses deficits of cognitive function and memory and increased heart rate induced by acute severe isovolemic anemia. Anesthesiology. 2002;96: 871-7.

58. Rigamonti A, McLaren AT, Mazer CD, Nix K, Ragoonanan T, Freedman J, et al. Storage of strain-specific rat blood limits cerebral tissue oxygen delivery during acute fluid resuscitation. Br J Anaesth. 2008;100:357-64.

59. Anand IS, Chandrashekhar Y, Ferrari R, Poole-Wilson PA, Harris PC. Pathogenesis of oedema in chronic severe anaemia: studies of body water and sodium, renal function, haemodynamic variables, and plasma hormones. $\mathrm{Br}$ Heart J. 1993;70:357-62.

60. Dec GW. Anemia and iron deficiency — new therapeutic targets in heart failure? N Engl J Med. 2009;361:2475-7.

61. Slogoff S, Reul GJ, Keats AS, Curry GR, Crum ME, Elmquist BA, et al. Role of perfusion pressure and flow in major organ dysfunction after cardiopulmonary bypass. Ann Thorac Surg. 1990;50:911-8.

62. Zanardo G, Michielon P, Paccagnella A, Rosi P, Caló M, Salandin V, et al. Acute renal failure in the patient undergoing cardiac operation. Prevalence, mortality rate, and main risk factors. J Thorac Cardiovasc Surg. 1994;107:1489-95.

63. Andersson LG, Bratteby LE, Ekroth R, Hallhagen S, Joachimsson PO, van der Linden J, et al. Renal function during cardiopulmonary bypass: influence of pump flow and systemic blood pressure. Eur J Cardiothorac Surg. 1994;8: 597-602.

64. Jeppsson A, Andersson LG, Ekroth R, Joachimsson PO. Renal hypoxanthine balance in cardiac surgery: effects of felodipine. J Cardiothorac Vasc Anesth. 1999;13:715-9. 
65. Karkouti K, Wijeysundera DN, Yau TM, Callum JL, Cheng DC, Crowther M, et al. Acute kidney injury after cardiac surgery: focus on modifiable risk factors. Circulation. 2009;119:495-502.

66. Velissaris T, Tang A, Murray M, El-Minshawy A, Hett D, Ohri S. A prospective randomized study to evaluate splanchnic hypoxia during beating-heart and conventional coronary revascularization. Eur J Cardiothorac Surg. 2003;23: 917-24.

67. Friedman G, Berlot G, Kahn RJ, Vincent JL. Combined measurements of blood lactate concentrations and gastric intramucosal $\mathrm{pH}$ in patients with severe sepsis. Crit Care Med. 1995;23:1184-93.

68. Zacharias A, Schwann TA, Parenteau GL, Riordan CJ, Durham SJ, Engoren M, et al. Predictors of gastrointestinal complications in cardiac surgery. Tex Heart Inst J. 2000;27:93-9.

69. Fiddian-Green RG, Baker S. Predictive value of the stomach wall $\mathrm{pH}$ for complications after cardiac operations: comparison with other monitoring. Crit Care Med. 1987;15:153-6.

70. Ruokonen E, Takala J, Kari A. Regional blood flow and oxygen transport in patients with the low cardiac output syndrome after cardiac surgery. Crit Care Med. 1993;21:1304-11.

71. Kuttila K, Niinikoski J, Haglund U. Visceral and peripheral tissue perfusion after cardiac surgery. Scand J Thorac Cardiovasc Surg. 1991;25:57-62.

72. Uusaro A, Ruokonen E, Takala J. Splanchnic oxygen transport after cardiac surgery: evidence for inadequate tissue perfusion after stabilization of hemodynamics. Intensive Care Med. 1996;22:26-33.

73. Thoren A, Nygren A, Houltz E, Ricksten SE. Cardiopulmonary bypass in humans-jejunal mucosal perfusion increases in parallel with wellmaintained microvascular hematocrit. Acta Anaesthesiol Scand. 2005;49: 502-9.

74. Berger K, Sander M, Spies CD, Weymann L, Bühner S, Lochs H, et al. Profound haemodilution during normothermic cardiopulmonary bypass influences neither gastrointestinal permeability nor cytokine release in coronary artery bypass graft surgery. Br J Anaesth. 2009;103:511-7.

75. Spahn DR, Dettori N, Kocian R, Chassot PG. Transfusion in the cardiac patient. Crit Care Clin. 2004;20:269-79.

76. Anderson JL, Adams CD, Antman EM, Bridges CR, Califf RM, Casey DE Jr, et al. ACC/AHA 2007 guidelines for the management of patients with unstable angina/non-ST-Elevation myocardial infarction: a report of the American College of Cardiology/American Heart Association Task Force on Practice Guidelines (Writing Committee to Revise the 2002 Guidelines for the Management of Patients With Unstable Angina/Non-ST-Elevation Myocardial Infarction) developed in collaboration with the American College of Emergency Physicians, the Society for Cardiovascular Angiography and Interventions, and the Society of Thoracic Surgeons endorsed by the American Association of Cardiovascular and Pulmonary Rehabilitation and the Society for Academic Emergency Medicine. J Am Coll Cardiol. 2007;50:e1-157. Erratum in: J Am Coll Cardiol. 2008;51:974.

77. Kushner FG, Hand M, Smith SC Jr, King SB 3rd, Anderson JL, Antman EM, et al. 2009 focused updates: ACC/AHA guidelines for the management of patients with ST-elevation myocardial infarction (updating the 2004 guideline and 2007 focused update) and ACC/AHA/SCAI guidelines on percutaneous coronary intervention (updating the 2005 guideline and 2007 focused update) a report of the American College of Cardiology Foundation/American Heart Association Task Force on Practice Guidelines. J Am Coll Cardiol. 2009;54: 2205-41. Erratum in: J Am Coll Cardiol. 2010;55:612. Dosage error in article text. J Am Coll Cardiol. 2009;54:2464.

78. Shore-Lesserson L, Manspeizer HE, DePerio M, Francis S, Vela-Cantos F, Ergin MA. Thromboelastography-guided transfusion algorithm reduces transfusions in complex cardiac surgery. Anesth Analg. 1999;88:312-9.

79. Gammie JS, Zenati M, Kormos RL, Hattler BG, Wei LM, Pellegrini RV, et al. Abciximab and excessive bleeding in patients undergoing emergency cardiac operations. Ann Thorac Surg. 1998;65:465-9.

80. Dyke CM. Safety of glycoprotein IIb-IIIa inhibitors: A heart surgeon's perspective. Am Heart J. 1999;138(4 Pt 2):307-16.

81. Yusuf S, Zhao F, Mehta SR, Chrolavicius S, Tognoni G, Fox KK, et al. Effects of clopidogrel in addition to aspirin in patients with acute coronary syndromes without ST-segment elevation. N Engl J Med. 2001;345:494-502. Erratum in: N Engl J Med. 2001;345:1506. N Engl J Med. 2001;345:1716.

82. Berger JS, Frye CB, Harshaw Q, Edwards FH, Steinhubl SR, Becker RC. Impact of clopidogrel in patients with acute coronary syndromes requiring coronary artery bypass surgery: a multicenter analysis. J Am Coll Cardiol. 2008; 52:1693-701.
83. Firanescu CE, Martens EJ, Schonberger JP, Soliman Hamad MA, van Straten AH. Postoperative blood loss in patients undergoing coronary artery bypass surgery after preoperative treatment with clopidogrel. A prospective randomised controlled study. Eur J Cardiothorac Surg. 2009;36:856-62.

84. Wiviott SD, Braunwald E, McCabe CH, Montalescot G, Ruzyllo W, Gottlieb S, et al. Prasugrel versus clopidogrel in patients with acute coronary syndromes. N Engl J Med. 2007;357:2001-15.

85. Mehta RH, Roe MT, Mulgund J, Ohman EM, Cannon CP, Gibler WB, et al Acute clopidogrel use and outcomes in patients with non-ST-segment elevation acute coronary syndromes undergoing coronary artery bypass surgery. $\mathrm{J} \mathrm{Am}$ Coll Cardiol. 2006;48:281-6.

86. Ebrahimi R, Dyke C, Mehran R, Manoukian SV, Feit F, Cox DA, et al. Outcomes following pre-operative clopidogrel administration in patients with acute coronary syndromes undergoing coronary artery bypass surgery: the ACUITY (Acute Catheterization and Urgent Intervention Triage strategY) trial. J Am Coll Cardiol. 2009;53:1965-72

87. Lemmer JH Jr, Metzdorff MT, Krause AH Jr, Martin MA, Okies JE, Hill JG Emergency coronary artery bypass graft surgery in abciximab-treated patients. Ann Thorac Surg. 2000;69:90-5.

88. Rahe-Meyer N, Winterhalter M, Boden A, Froemke C, Piepenbrock S, Calatzis A, et al. Platelet concentrates transfusion in cardiac surgery and platelet function assessment by multiple electrode aggregometry. Acta Anaesthesiol Scand. 2009;53:168-75.

89. Bryson GL, Laupacis A, Wells GA. Does acute normovolemic hemodilution reduce perioperative allogeneic transfusion? A meta-analysis. The International Study of Perioperative Transfusion. Anesth Analg. 1998;86:9-15.

90. Goodnough LT, Despotis GJ, Merkel K, Monk TG. A randomized trial comparing acute normovolemic hemodilution and preoperative autologous blood donation in total hip arthroplasty. Transfusion. 2000;40:1054-7.

91. Matot I, Scheinin O, Jurim O, Eid A. Effectiveness of acute normovolemic hemodilution to minimize allogeneic blood transfusion in major liver resections. Anesthesiology. 2002;97:794-800.

92. Jalali A, Naseri MH, Chalian M, Dolatabadi HL. Acute normovolaemic haemodilution with crystalloids in coronary artery bypass graft surgery: a preliminary survey of haemostatic markers. Acta Cardiol. 2008;63:335-9.

93. Sharma V, Talwar S, Choudhary SK, Lakshmy R, Kale S, Kumar AS. Evaluation of Epsilon amino-caproic acid (EACA) and autologous blood as blood conservation strategies in patients undergoing cardiac surgery. Heart Lung Circ. 2006; 15:261-5

94. Casati V, Benussi S, Sandrelli L, Grasso MA, Spagnolo S, D’Angelo A. Intraoperative moderate acute normovolemic hemodilution associated with a comprehensive blood-sparing protocol in off-pump coronary surgery. Anesth Analg. 2004;98:1217-23, table of contents.

95. Greenburg AG, Kim HW, Hemolink Study Group. Use of an oxygen therapeutic as an adjunct to intraoperative autologous donation to reduce transfusion requirements in patients undergoing coronary artery bypass graft surgery. $J \mathrm{Am}$ Coll Surg. 2004;198:373-85

96. Kahraman S, Altunkaya H, Celebioğlu B, Kanbak M, Pasaoğlu I, Erdem K. The effect of acute normovolemic hemodilution on homologous blood requirements and total estimated red blood cell volume lost. Acta Anaesthesiol Scand. 1997 41:614-7.

97. Helm RE, Klemperer JD, Rosengart TK, Gold JP, Peterson P, DeBois W, et al Intraoperative autologous blood donation preserves red cell mass but does no decrease postoperative bleeding. Ann Thorac Surg. 1996;62:1431-41.

98. Mathew JP, Mackensen GB, Phillips-Bute B, Stafford-Smith M, Podgoreanu MV, Grocott HP, et al. Effects of extreme hemodilution during cardiac surgery on cognitive function in the elderly. Anesthesiology. 2007;107:577-84

99. Weiskopf RB. Hemodilution and candles. Anesthesiology. 2002;97:773-5.

100. Carson JL, Noveck H, Berlin JA, Gould SA. Mortality and morbidity in patients with very low postoperative $\mathrm{Hb}$ levels who decline blood transfusion. Transfusion. 2002;42:812-8.

101. Crystal GJ, El-Orbany M, Zhou X, Salem MR, Kim SJ. Hemodilution does not alter the coronary vasodilating effects of endogenous or exogenous nitric oxide. Can J Anaesth. 2008;55:507-14

102. Forgie MA, Wells PS, Laupacis A, Fergusson D. Preoperative autologous donation decreases allogeneic transfusion but increases exposure to all red blood cell transfusion: results of a meta-analysis. International Study of Perioperative Transfusion (ISPOT) Investigators. Arch Intern Med. 1998;158:610-6.

103. Henry DA, Carless PA, Moxey AJ, O'Connell D, Forgie MA, Wells PS, et al Pre-operative autologous donation for minimising perioperative allogeneic blood transfusion (Review). Cochrane Database Syst Rev. 2002;2:CD003602. 
104. Bouchard D, Marcheix B, Al-Shamary S, Vanden Eynden F, Demers P, Robitaille D, et al. Preoperative autologous blood donation reduces the need for allogeneic blood products: a prospective randomized study. Can J Surg. 2008;51:422-7.

105. Dietrich W, Thuermel K, Heyde S, Busley R, Berger K. Autologous blood donation in cardiac surgery: reduction of allogeneic blood transfusion and cost-effectiveness. J Cardiothorac Vasc Anesth. 2005;19:589-96.

106. Jones JW, McCoy TA, Rawitscher RE, Lindsley DA. Effects of intraoperative plasmapheresis on blood loss in cardiac surgery. Ann Thorac Surg. 1990;49: 585-90.

107. DelRossi AJ, Cernaianu AC, Vertrees RA, Wacker CJ, Fuller SJ, Cilley JH Jr, et al. Platelet-rich plasma reduces postoperative blood loss after cardiopulmonary bypass. J Thorac Cardiovasc Surg. 1990;100:281-6.

108. Christenson JT, Reuse J, Badel P, Simonet F, Schmuziger M. Plateletpheresis before redo CABG diminishes excessive blood transfusion. Ann Thorac Surg. 1996;62:1373-9.

109. Menges T, Welters I, Wagner RM, Boldt J, Dapper F, Hempelmann G. The influence of acute preoperative plasmapheresis on coagulation tests, fibrinolysis, blood loss and transfusion requirements in cardiac surgery. Eur J Cardiothorac Surg. 1997;11:557-63.

110. Stover EP, Siegel LC, Hood PA, O'Riordan GE, McKenna TR. Platelet-rich plasma sequestration, with therapeutic platelet yields, reduces allogeneic transfusion in complex cardiac surgery. Anesth Analg. 2000;90:509-16.

111. Tobe CE, Vocelka C, Sepulvada R, Gillis B, Nessly M, Verrier ED, et al. Infusion of autologous platelet rich plasma does not reduce blood loss and product use after coronary artery bypass. A prospective, randomized, blinded study. $J$ Thorac Cardiovasc Surg. 1993;105:1007-14.

112. Ereth MH, Oliver WC Jr, Beynen FM, Mullany CJ, Orszulak TA, Santrach PJ, et al. Autologous platelet-rich plasma does not reduce transfusion of homologous blood products in patients undergoing repeat valvular surgery. Anesthesiology. 1993;79:540-7; discussion 27A.

113. Wong CA, Franklin ML, Wade LD. Coagulation tests, blood loss, and transfusion requirements in platelet-rich plasmapheresed versus nonpheresed cardiac surgery patients. Anesth Analg. 1994;78:29-36.

114. Shore-Lesserson L, Reich DL, DePerio M, Silvay G. Autologous platelet-rich plasmapheresis: risk versus benefit in repeat cardiac operations. Anesth Analg. 1995;81:229-35.

115. Ford SM, Unsworth-White MJ, Aziz T, Tooze JA, van Besouw JP, Bevan DH, et al. Platelet pheresis is not a useful adjunct to blood-sparing strategies in cardiac surgery. J Cardiothorac Vasc Anesth. 2002;16:321-9.

116. Wajon P, Gibson J, Calcroft R, Hughes C, Thrift B. Intraoperative plateletpheresis and autologous platelet gel do not reduce chest tube drainage or allogeneic blood transfusion after reoperative coronary artery bypass graft. Anesth Analg. 2001;93:536-42.

117. Armellin G, Sorbara C, Bonato R, Pittarello D, Dal Cero P, Giron G. Intraoperative plasmapheresis in cardiac surgery. J Cardiothorac Vasc Anesth. 1997;11:13-7.

118. Boey SK, Ong BC, Dhara SS. Preoperative plateletpheresis does not reduce blood loss during cardiac surgery. Can J Anaesth. 1993;40:844-50.

119. Rubens FD, Fergusson D, Wells PS, Huang M, McGowan JL, Laupacis A. Platelet-rich plasmapheresis in cardiac surgery: a meta-analysis of the effect on transfusion requirements. J Thorac Cardiovasc Surg. 1998;116:641-7.

120. Carless PA, Rubens FD, Anthony DM, O'Connell D, Henry DA. Platelet-richplasmapheresis for minimising peri-operative allogeneic blood transfusion. Cochrane Database Syst Rev. 2003;2:CD004172.

121. Gallandat Huet RC, Siemons AW, Baus D, van Rooyen-Butijn WT, Haagenaars JA, van Oeveren W, et al. A novel hydroxyethyl starch (Voluven) for effective perioperative plasma volume substitution in cardiac surgery. Can J Anaesth. 2000;47:1207-15.

122. Franz A, Bräunlich P, Gamsjäger T, Felfernig M, Gustorff B, KozekLangenecker SA. The effects of hydroxyethyl starches of varying molecular weights on platelet function. Anesth Analg. 2001;92:1402-7.

123. Kasper SM, Meinert P, Kampe S, Görg C, Geisen C, Mehlhorn U, et al. Largedose hydroxyethyl starch 130/0.4 does not increase blood loss and transfusion requirements in coronary artery bypass surgery compared with hydroxyethyl starch 200/0.5 at recommended doses. Anesthesiology. 2003;99:42-7.

124. Ickx BE, Bepperling F, Melot C, Schulman C, Van der Linden PJ. Plasma substitution effects of a new hydroxyethyl starch HES 130/0.4 compared with HES 200/0.5 during and after extended acute normovolaemic haemodilution. $\mathrm{Br} J$ Anaesth. 2003;91:196-202.

125. Jungheinrich C, Sauermann W, Bepperling F, Vogt NH. Volume efficacy and reduced influence on measures of coagulation using hydroxyethyl starch 130/0.4
$(6 \%)$ with an optimised in vivo molecular weight in orthopaedic surgery: a randomised, double-blind study. Drugs R D. 2004;5:1-9.

126. Despotis GJ, Santoro SA, Spitznagel E, Kater KM, Cox JL, Barnes P, et al. Prospective evaluation and clinical utility of on-site monitoring of coagulation in patients undergoing cardiac operation. J Thorac Cardiovasc Surg. 1994;107: 271-9.

127. Boks RH, Wijers MJ, Hofland J, Takkenberg JJ, Bogers AJ. Low molecular starch versus gelatin plasma expander during $\mathrm{CPB}$ : does it make a difference? Perfusion. 2007;22:333-7.

128. Van der Linden PJ, De Hert SG, Deraedt D, Cromheecke S, De Decker K, De Paep R, et al. Hydroxyethyl starch 130/0.4 versus modified fluid gelatin for volume expansion in cardiac surgery patients: the effects on perioperative bleeding and transfusion needs. Anesth Analg. 2005;101:629-34, table of contents.

129. Van der Linden PJ, De Hert SG, Daper A, Trenchant A, Schmartz D, Defrance P, et al. $3.5 \%$ urea-linked gelatin is as effective as $6 \%$ HES $200 / 0.5$ for volume management in cardiac surgery patients. Can J Anaesth. 2004;51:236-41.

130. Ooi JS, Ramzisham AR, Zamrin MD. Is $6 \%$ hydroxyethyl starch 130/0.4 safe in coronary artery bypass graft surgery? Asian Cardiovasc Thorac Ann. 2009;17: 368-72.

131. Tigchelaar I, Gallandat Huet RC, Korsten J, Boonstra PW, van Oeveren W. Hemostatic effects of three colloid plasma substitutes for priming solution in cardiopulmonary bypass. Eur J Cardiothorac Surg. 1997;11:626-32.

132. Finfer S, Bellomo R, Boyce N, French J, Myburgh J, Norton R, et al. A comparison of albumin and saline for fluid resuscitation in the intensive care unit. N Engl J Med. 2004;350:2247-56.

133. Russell JA, Navickis RJ, Wilkes MM. Albumin versus crystalloid for pump priming in cardiac surgery: meta-analysis of controlled trials. $J$ Cardiothorac Vasc Anesth. 2004;18:429-37.

134. Boks RH, van Herwerden LA, Takkenberg JJ, van Oeveren W, Gu YJ, Wijers MJ, et al. Is the use of albumin in colloid prime solution of cardiopulmonary bypass circuit justified? Ann Thorac Surg. 2001;72:850-3.

135. Kozek-Langenecker SA, Jungheinrich C, Sauermann W, Van der Linden P. The effects of hydroxyethyl starch 130/0.4 (6\%) on blood loss and use of blood products in major surgery: a pooled analysis of randomized clinical trials. Anesth Analg. 2008;107:382-90.

136. Wheeldon DR, Bethune DW, Gill RD. Vortex pumping for routine cardiac surgery: a comparative study. Perfusion. 1990;5:135-43.

137. Parault BC, Conrad SA. The effect of extracorporeal circulation time and patient age on platelet retention during cardiopulmonary bypass: a comparison of roller and centrifugal pumps. J Extra Corpor Technol. 1991;23:34-8.

138. Jensen E, Andréasson S, Bengtsson A, Berggren H, Ekroth R, Lindholm L, et al. Influence of two different perfusion systems on inflammatory response in pediatric heart surgery. Ann Thorac Surg. 2003;75:919-25.

139. Schönberger JP, Everts PA, Hoffmann JJ. Systemic blood activation with open and closed venous reservoirs. Ann Thorac Surg. 1995;59:1549-55.

140. Aldea GS, Soltow LO, Chandler WL, Triggs CM, Vocelka CR, Crockett GI, et al. Limitation of thrombin generation, platelet activation, and inflammation by elimination of cardiotomy suction in patients undergoing coronary artery bypass grafting treated with heparin-bonded circuits. J Thorac Cardiovasc Surg. 2002;123:742-55.

141. Lindholm L, Westerberg M, Bengtsson A, Ekroth R, Jensen E, Jeppsson A. A closed perfusion system with heparin coating and centrifugal pump improves cardiopulmonary bypass biocompatibility in elderly patients. Ann Thorac Surg. 2004;78:2131-8.

142. Nuttall GA, Oliver WC, Fass DN, Owen WG, Dinenno D, Ereth MH, et al. A prospective, randomized platelet-function study of heparinized oxygenators and cardiotomy suction. J Cardiothorac Vasc Anesth. 2006;20:554-61.

143. Jewell AE, Akowuah EF, Suvarna SK, Braidley P, Hopkinson D, Cooper G. A prospective randomised comparison of cardiotomy suction and cell saver for recycling shed blood during cardiac surgery. Eur J Cardiothorac Surg. 2003;23:633-6.

144. Rubens FD, Boodhwani M, Mesana T, Wozny D, Wells G, Nathan HJ, et al. The cardiotomy trial: a randomized, double-blind study to assess the effect of processing of shed blood during cardiopulmonary bypass on transfusion and neurocognitive function. Circulation. 2007;116(11 Suppl):I89-97.

145. de Haan J, Boonstra PW, Monnink SH, Ebels T, van Oeveren W. Retransfusion of suctioned blood during cardiopulmonary bypass impairs hemostasis. Ann Thorac Surg. 1995;59:901-7.

146. De Somer F, Van Belleghem Y, Caes F, Francois K, Van Overbeke H, Arnout J, et al. Tissue factor as the main activator of the coagulation system during cardiopulmonary bypass. J Thorac Cardiovasc Surg. 2002;123:951-8. 
147. Jansen PG, Baufreton C, Le Besnerais P, Loisance DY, Wildevuur CR. Heparincoated circuits and aprotinin prime for coronary artery bypass grafting. Ann Thorac Surg. 1996;61:1363-6.

148. Oliver WC Jr, Nuttall GA, Ereth MH, Santrach PJ, Buda DA, Schaff HV. Heparincoated versus uncoated extracorporeal circuit in patients undergoing coronary artery bypass graft surgery. J Cardiothorac Vasc Anesth. 2003;17:165-70.

149. Inui K, Shimazaki Y, Watanabe T, Takahashi T, Minowa T, Takeda H, et al. Effects of Duraflo II heparin-coated cardiopulmonary bypass circuits on the coagulation system, endothelial damage, and cytokine release in patients with cardiac operation employing aprotinin and steroids. Artif Organs. 1999;23:1107-12.

150. Videm V, Mollnes TE, Fosse E, Mohr B, Bergh K, Hagve TA, et al. Heparincoated cardiopulmonary bypass equipment. I. Biocompatibility markers and development of complications in a high-risk population. J Thorac Cardiovasc Surg. 1999;117:794-802.

151. Borowiec J, Thelin S, Bagge L, Hultman J, Hansson HE. Decreased blood loss after cardiopulmonary bypass using heparin-coated circuit and $50 \%$ reduction of heparin dose. Scand J Thorac Cardiovasc Surg. 1992;26:177-85.

152. Parolari A, Alamanni F, Gherli T, Salis S, Spirito R, Foieni F, et al. 'High dose' aprotinin and heparin-coated circuits: clinical efficacy and inflammatory response. Cardiovasc Surg. 1999;7:117-27.

153. Dickinson T, Mahoney CB, Simmons M, Marison A, Polanski P. Trilliumcoated oxygenators in adult open-heart surgery: a prospective randomized trial. J Extra Corpor Technol. 2002;34:248-53.

154. Gunaydin S, Farsak B, Kocakulak M, Sari T, Yorgancioglu C, Zorlutuna Y. Clinical performance and biocompatibility of poly(2-methoxyethylacrylate)-coated extracorporeal circuits. Ann Thorac Surg. 2002;74:819-24.

155. Edmunds LH Jr, Colman RW. Thrombin during cardiopulmonary bypass. Ann Thorac Surg. 2006;82:2315-22.

156. Wildevuur CR, Jansen PG, Bezemer PD, Kuik DJ, Eijsman L, Bruins P, et al. Clinical evaluation of Duraflo II heparin treated extracorporeal circulation circuits (2nd version). The European Working Group on heparin coated extracorporeal circulation circuits. Eur J Cardiothorac Surg. 1997;11:616-25.

157. Ranucci M, Mazzucco A, Pessotto R, Grillone G, Casati V, Porreca L, et al. Heparin-coated circuits for high-risk patients: a multicenter, prospective, randomized trial. Ann Thorac Surg. 1999;67:994-1000.

158. Mangoush O, Purkayastha S, Haj-Yahia S, Kinross J, Hayward M, Bartolozzi F, et al. Heparin-bonded circuits versus nonheparin-bonded circuits: an evaluation of their effect on clinical outcomes. Eur J Cardiothorac Surg. 2007;31:1058-69.

159. Ranucci M, Balduini A, Ditta A, Boncilli A, Brozzi S. A systematic review of biocompatible cardiopulmonary bypass circuits and clinical outcome. Ann Thorac Surg. 2009;87:1311-9.

160. Shuhaibar MN, Hargrove M, Millat MH, O'Donnell A, Aherne T. How much heparin do we really need to go on pump? A rethink of current practices. Eur J Cardiothorac Surg. 2004;26:947-50.

161. Mirow N, Brinkmann T, Minami K, Tenderich G, Schulte-Eistrup S, Kleesiek K, et al. Low dose systemic heparinization combined with heparincoated extracorporeal circulation. Effects related to platelets. J Cardiovasc Surg (Torino). 2001;42:579-85.

162. Mullen JC, Bentley MJ, Gelfand ET, Koshal A, Modry DL, Guenther CR, et al. Coronary artery bypass surgery with heparin-coated perfusion circuits and lowdose heparinization. Can J Surg. 2002;45:166-72.

163. Ovrum E, Am Holen E, Tangen G, Ringdal MA. Heparinized cardiopulmonary bypass and full heparin dose marginally improve clinical performance. Ann Thorac Surg. 1996;62:1128-33.

164. Ovrum E, Brosstad F, Am Holen E, Tangen G, Abdelnoor M, Oystese R. Complete heparin-coated (CBAS) cardiopulmonary bypass and reduced systemic heparin dose; effects on coagulation and fibrinolysis. Eur J Cardiothorac Surg. 1996;10:449-55.

165. Aldea GS, O'Gara P, Shapira OM, Treanor P, Osman A, Patalis E, et al. Effect of anticoagulation protocol on outcome in patients undergoing CABG with heparin-bonded cardiopulmonary bypass circuits. Ann Thorac Surg. 1998;65: 425-33.

166. Ranucci M, Cazzaniga A, Soro G, Isgrò G, Frigiola A, Menicanti L. The antithrombin III-saving effect of reduced systemic heparinization and heparincoated circuits. J Cardiothorac Vasc Anesth. 2002;16:316-20.

167. von Segesser LK, Weiss BM, Pasic M, Garcia E, Turina MI. Risk and benefit of low systemic heparinization during open heart operations. Ann Thorac Surg. 1994;58:391-8.

168. Ovrum E, Holen EA, Tangen G, Brosstad F, Abdelnoor M, Ringdal MA, et al. Completely heparinized cardiopulmonary bypass and reduced systemic heparin: clinical and hemostatic effects. Ann Thorac Surg. 1995;60:365-71.
169. Fang WC, Helm RE, Krieger KH, Rosengart TK, DuBois WJ, Sason C, et al Impact of minimum hematocrit during cardiopulmonary bypass on mortality in patients undergoing coronary artery surgery. Circulation. 1997;96(9 Suppl):II194-9.

170. DeFoe GR, Ross CS, Olmstead EM, Surgenor SD, Fillinger MP, Groom RC, et al. Lowest hematocrit on bypass and adverse outcomes associated with coronary artery bypass grafting. Northern New England Cardiovascular Disease Study Group. Ann Thorac Surg. 2001;71:769-76.

171. Habib RH, Zacharias A, Schwann TA, Riordan CJ, Durham SJ, Shah A. Adverse effects of low hematocrit during cardiopulmonary bypass in the adult: should current practice be changed? J Thorac Cardiovasc Surg. 2003;125: 1438-50.

172. Swaminathan M, Phillips-Bute BG, Conlon PJ, Smith PK, Newman MF, Stafford-Smith $\mathrm{M}$. The association of lowest hematocrit during cardiopulmonary bypass with acute renal injury after coronary artery bypass surgery. Ann Thorac Surg. 2003;76:784-92

173. Karkouti K, Beattie WS, Wijeysundera DN, Rao V, Chan C, Dattilo KM, et al. Hemodilution during cardiopulmonary bypass is an independent risk factor for acute renal failure in adult cardiac surgery. J Thorac Cardiovasc Surg. 2005; 129:391-400

174. Ranucci M, Biagioli B, Scolletta S, Grillone G, Cazzaniga A, Cattabriga I, et al Lowest hematocrit on cardiopulmonary bypass impairs the outcome in coronary surgery: An Italian Multicenter Study from the National Cardioanesthesia Database. Tex Heart Inst J. 2006;33:300-5.

175. Huybregts RA, Morariu AM, Rakhorst G, Spiegelenberg SR, Romijn HW, de Vroege R, et al. Attenuated renal and intestinal injury after use of a minicardiopulmonary bypass system. Ann Thorac Surg. 2007;83:1760-6.

176. Remadi JP, Rakotoarivelo Z, Marticho P, Benamar A. Prospective randomized study comparing coronary artery bypass grafting with the new miniextracorporeal circulation Jostra System or with a standard cardiopulmonary bypass. Am Heart J. 2006;151:198.

177. Perthel M, El-Ayoubi L, Bendisch A, Laas J, Gerigk M. Clinical advantages of using mini-bypass systems in terms of blood product use, postoperative bleeding and air entrainment: an in vivo clinical perspective. Eur J Cardiothorac Surg. 2007;31: 1070-5. Erratum in: Eur J Cardiothorac Surg. 2007;32:952.

178. Castiglioni A, Verzini A, Pappalardo F, Colangelo N, Torracca L, Zangrillo A et al. Minimally invasive closed circuit versus standard extracorporeal circulation for aortic valve replacement. Ann Thorac Surg. 2007;83:586-91.

179. Sakwa MP, Emery RW, Shannon FL, Altshuler JM, Mitchell D, Zwada D, et al Coronary artery bypass grafting with a minimized cardiopulmonary bypass circuit: a prospective, randomized trial. J Thorac Cardiovasc Surg. 2009;137: 481-5.

180. Kamiya H, Kofidis T, Haverich A, Klima U. Preliminary experience with the mini-extracorporeal circulation system (Medtronic resting heart system). Interact Cardiovasc Thorac Surg. 2006;5:680-2.

181. Remadi JP, Rakotoarivello Z, Marticho P, Trojette F, Benamar A, Poulain H, et al. Aortic valve replacement with the minimal extracorporeal circulation (Jostra MECC System) versus standard cardiopulmonary bypass: a randomized prospective trial. J Thorac Cardiovasc Surg. 2004;128:436-41.

182. Beghi C, Nicolini F, Agostinelli A, Borrello B, Budillon AM, Bacciottini F, et al. Mini-cardiopulmonary bypass system: results of a prospective randomized study. Ann Thorac Surg. 2006;81:1396-400.

183. Ranucci M, Castelvecchio S. Management of mini-cardiopulmonary bypass devices: is it worth the energy? Curr Opin Anaesthesiol. 2009;22:78-83.

184. Engoren M, Habib RH, Hadaway J, Zacharias A, Schwann TA, Riordan CJ, et al. The effect on long-term survival of erythrocyte transfusion given for cardiac valve operations. Ann Thorac Surg. 2009;88:95-100, 100.e1-3.

185. Tyson GH 3rd, Rodriguez E, Elci OC, Koutlas TC, Chitwood WR Jr Ferguson TB, et al. Cardiac procedures in patients with a body mass index exceeding 45: outcomes and long-term results. Ann Thorac Surg. 2007;84:3-9.

186. Karkouti K, Wijeysundera DN, Yau TM, Beattie WS, Abdelnaem E, McCluskey SA, et al. The independent association of massive blood loss with mortality in cardiac surgery. Transfusion. 2004;44:1453-62.

187. Ali ZA, Lim E, Motalleb-Zadeh R, Ali AA, Callaghan CJ, Gerrard C, et al. Allogenic blood transfusion does not predispose to infection after cardiac surgery. Ann Thorac Surg. 2004;78:1542-6.

188. Ryan T, Mc Carthy JF, Rady MY, Serkey J, Gordon S, Starr NJ, et al. Early bloodstream infection after cardiopulmonary bypass: frequency rate, risk factors, and implications. Crit Care Med. 1997;25:2009-14.

189. Sreeram GM, Welsby IJ, Sharma AD, Phillips-Bute B, Smith PK, Slaughter TF Infectious complications after cardiac surgery: lack of association with fresh 
frozen plasma or platelet transfusions. J Cardiothorac Vasc Anesth. 2005;19: 430-4.

190. Sharma AD, Slaughter TF, Clements FM, Sreeram G, Newman MF, PhillipsBute B, et al. Association of leukocyte-depleted blood transfusions with infectious complications after cardiac surgery. Surg Infect (Larchmt). 2002;3:127-33.

191. Rosmarakis ES, Prapas SN, Rellos K, Michalopoulos A, Samonis G, Falagas ME. Nosocomial infections after off-pump coronary artery bypass surgery: frequency, characteristics, and risk factors. Interact Cardiovasc Thorac Surg. 2007;6:759-67.

192. Whitson BA, Huddleston SJ, Savik K, Shumway SJ. Risk of adverse outcomes associated with blood transfusion after cardiac surgery depends on the amount of transfusion. J Surg Res. 2010;158:20-7.

193. Rogers MA, Blumberg N, Saint SK, Kim C, Nallamothu BK, Langa KM. Allogeneic blood transfusions explain increased mortality in women after coronary artery bypass graft surgery. Am Heart J. 2006;152:1028-34.

194. Rogers MA, Blumberg N, Heal JM, Hicks GL Jr. Increased risk of infection and mortality in women after cardiac surgery related to allogeneic blood transfusion. J Womens Health (Larchmt). 2007;16:1412-20.

195. Chelemer SB, Prato BS, Cox PM Jr, O'Connor GT, Morton JR. Association of bacterial infection and red blood cell transfusion after coronary artery bypass surgery. Ann Thorac Surg. 2002;73:138-42.

196. Bucerius J, Gummert JF, Walther T, Schmitt DV, Doll N, Falk V, et al. On-pump versus off-pump coronary artery bypass grafting: impact on postoperative renal failure requiring renal replacement therapy. Ann Thorac Surg. 2004;77:1250-6.

197. Bove T, Calabrò MG, Landoni G, Aletti G, Marino G, Crescenzi G, et al. The incidence and risk of acute renal failure after cardiac surgery. $J$ Cardiothorac Vasc Anesth. 2004;18:442-5.

198. Surgenor SD, DeFoe GR, Fillinger MP, Likosky DS, Groom RC, Clark C, et al. Intraoperative red blood cell transfusion during coronary artery bypass graft surgery increases the risk of postoperative low-output heart failure. Circulation. 2006;114(1 Suppl):I43-8.

199. De Santo L, Romano G, Della Corte A, de Simone V, Grimaldi F, Cotrufo M, et al. Preoperative anemia in patients undergoing coronary artery bypass grafting predicts acute kidney injury. J Thorac Cardiovasc Surg. 2009;138:965-70.

200. Hébert PC, Wells G, Blajchman MA, Marshall J, Martin C, Pagliarello G, et al. A multicenter, randomized, controlled clinical trial of transfusion requirements in critical care. Transfusion Requirements in Critical Care Investigators, Canadian Critical Care Trials Group. N Engl J Med. 1999;340:409-17.

201. Deans KJ, Minneci PC, Suffredini AF, Danner RL, Hoffman WD, Ciu X, et al. Randomization in clinical trials of titrated therapies: unintended consequences of using fixed treatment protocols. Crit Care Med. 2007;35:1509-16.

202. Fergusson D, Khanna MP, Tinmouth A, Hébert PC. Transfusion of leukoreduced red blood cells may decrease postoperative infections: two metaanalyses of randomized controlled trials. Can J Anaesth. 2004;51:417-24.

203. Vamvakas EC. Why have meta-analyses of randomized controlled trials of the association between non-white-blood-cell-reduced allogeneic blood transfusion and postoperative infection produced discordant results? Vox Sang. 2007;93: 196-207.

204. Vamvakas EC. White-blood-cell-containing allogeneic blood transfusion and postoperative infection or mortality: an updated meta-analysis. Vox Sang. 2007;92:224-32.

205. Yap CH, Lau L, Krishnaswamy M, Gaskell M, Yii M. Age of transfused red cells and early outcomes after cardiac surgery. Ann Thorac Surg. 2008;86:554-9.

206. Tinmouth A, Fergusson D, Yee IC, Hébert PC, ABLE Investigators; Canadian Critical Care Trials Group. Clinical consequences of red cell storage in the critically ill. Transfusion. 2006;46:2014-27.

207. Adamson JW. New blood, old blood, or no blood? N Engl J Med. 2008;358: 1295-6.

208. Raat NJ, Hilarius PM, Johannes T, de Korte D, Ince C, Verhoeven AJ. Rejuvenation of stored human red blood cells reverses the renal microvascular oxygenation deficit in an isovolemic transfusion model in rats. Transfusion. 2009;49: 427-34.

209. Kim YS, Murkin JM, Adams SJ. In vivo and in vitro evaluation of the heparin management test versus the activated coagulation time for monitoring anticoagulation level in aprotinin-treated patients during cardiac surgery. Heart Surg Forum. 2004; 7:E599-604.

210. Lilly KJ, O'Gara PJ, Treanor PR, Crowley R, Reardon DL, Shapira OM, et al. Heparin-bonded circuits without a cardiotomy: a description of a minimally invasive technique of cardiopulmonary bypass. Perfusion. 2002;17:95-7.

211. Raivio P, Kuitunen A, Petäjä J, Ilveskero S, Lassila R. Monitoring high-dose heparinization during cardiopulmonary by-pass-a comparison between prothrombinase-induced clotting time (PiCT) and two chromogenic antifactor Xa activity assays. Thromb Haemost. 2008;99:427-34.

212. Shirota K, Watanabe T, Takagi Y, Ohara Y, Usui A, Yasuura K. Maintenance of blood heparin concentration rather than activated clotting time better preserves the coagulation system in hypothermic cardiopulmonary bypass. Artif Organs. 2000;24:49-56.

213. Despotis GJ, Joist JH, Hogue CW Jr, Alsoufiev A, Joiner-Maier D, Santoro SA, et al. More effective suppression of hemostatic system activation in patients undergoing cardiac surgery by heparin dosing based on heparin blood concentrations rather than ACT. Thromb Haemost. 1996;76:902-8.

214. Jobes DR, Aitken GL, Shaffer GW. Increased accuracy and precision of heparin and protamine dosing reduces blood loss and transfusion in patients undergoing primary cardiac operations. J Thorac Cardiovasc Surg. 1995;110:36-45.

215. Ohata T, Sawa Y, Ohtake S, Nishimura M, Chan CJ, Suzuki K, et al. Clinical role of blood heparin level monitoring during open heart surgery. Jpn J Thorac Cardiovasc Surg. 1999;47:600-6.

216. Wippermann J, Albes JM, Hartrumpf M, Kaluza M, Vollandt R, Bruhin R, et al. Comparison of minimally invasive closed circuit extracorporeal circulation with conventional cardiopulmonary bypass and with off-pump technique in CABG patients: selected parameters of coagulation and inflammatory system. Eur J Cardiothorac Surg. 2005;28:127-32.

217. Capraro L, Kuitunen A, Salmenperä M, Kekomäki R. On-site coagulation monitoring does not affect hemostatic outcome after cardiac surgery. Acta Anaesthesiol Scand. 2001;45:200-6.

218. De Caterina R, Lanza M, Manca G, Strata GB, Maffei S, Salvatore L. Bleeding time and bleeding: an analysis of the relationship of the bleeding time test with parameters of surgical bleeding. Blood. 1994;84:3363-70.

219. Khuri SF, Wolfe JA, Josa M, Axford TC, Szymanski I, Assousa S, et al. Hematologic changes during and after cardiopulmonary bypass and their relationship to the bleeding time and nonsurgical blood loss. J Thorac Cardiovasc Surg. 1992;104:94-107.

220. Whitten CW, Greilich PE, Ivy R, Burkhardt D, Allison PM. D-Dimer formation during cardiac and noncardiac thoracic surgery. Anesth Analg. 1999;88:1226-31.

221. Whitten CW. Does D-dimer formation in patients undergoing cardiopulmonary bypass (CPB) reflect primary fibrinolysis? J Cardiothorac Vasc Anesth. 1997; 11:537-8.

222. Whitten CW, Allison PM, Latson TW, Ivy R, Burkhardt D, Gulden RH, et al. Evaluation of laboratory coagulation and lytic parameters resulting from autologous whole blood transfusion during primary aortocoronary artery bypass grafting. J Clin Anesth. 1996;8:229-35.

223. Davidson SJ, McGrowder D, Roughton M, Kelleher AA. Can ROTEM thromboelastometry predict postoperative bleeding after cardiac surgery? J Cardiothorac Vasc Anesth. 2008;22:655-61.

224. Ak K, Isbir CS, Tetik S, Atalan N, Tekeli A, Aljodi M, et al. Thromboelastography-based transfusion algorithm reduces blood product use after elective CABG: a prospective randomized study. J Card Surg. 2009;24:404-10.

225. Cammerer U, Dietrich W, Rampf T, Braun SL, Richter JA. The predictive value of modified computerized thromboelastography and platelet function analysis for postoperative blood loss in routine cardiac surgery. Anesth Analg. 2003; 96:51-7, table of contents.

226. Mengistu AM, Rohm KD, Boldt J, Mayer J, Suttner SW, Piper SN. The influence of aprotinin and tranexamic acid on platelet function and postoperative blood loss in cardiac surgery. Anesth Analg. 2008;107:391-7.

227. Nuttall GA, Oliver WC, Santrach PJ, Bryant S, Dearani JA, Schaff HV, et al. Efficacy of a simple intraoperative transfusion algorithm for nonerythrocyte component utilization after cardiopulmonary bypass. Anesthesiology. 2001; 94:773-81; discussion 5A-6A.

228. Royston D, von Kier S. Reduced haemostatic factor transfusion using heparinase-modified thrombelastography during cardiopulmonary bypass. $\mathrm{Br}$ J Anaesth. 2001;86:575-8.

229. Pleym H, Wahba A, Bjella L, Stenseth R. Sonoclot analysis in elderly compared with younger patients undergoing coronary surgery. Acta Anaesthesiol Scand. 2008;52:28-35.

230. Ereth MH, Nuttall GA, Ericson DG, Cooney WP 4th, Fisher BR, Oliver WC Jr, et al. Platelet glass bead retention predicts bleeding after cardiac surgery. $J$ Cardiothorac Vasc Anesth. 2001;15:49-54.

231. Despotis GJ, Levine V, Saleem R, Spitznagel E, Joist JH. Use of point-of-care test in identification of patients who can benefit from desmopressin during cardiac surgery: a randomised controlled trial. Lancet. 1999;354:106-10.

232. Faraday N, Guallar E, Sera VA, Bolton ED, Scharpf RB, Cartarius AM, et al. Utility of whole blood hemostatometry using the clot signature analyzer for 
assessment of hemostasis in cardiac surgery. Anesthesiology. 2002;96: 1115-22.

233. Nuttall GA, Oliver WC, Beynen FM, Santrach PJ, Strickland RA, Murray MJ. Determination of normal versus abnormal activated partial thromboplastin time and prothrombin time after cardiopulmonary bypass. J Cardiothorac Vasc Anesth. 1995;9:355-61.

234. Nuttall GA, Oliver WC, Ereth MH, Santrach PJ. Coagulation tests predict bleeding after cardiopulmonary bypass. J Cardiothorac Vasc Anesth. 1997; 11:815-23.

235. Mannucci PM, Levi M. Prevention and treatment of major blood loss. $N$ Engl J Med. 2007;356:2301-11.

236. Richardson DW, Robinson AG. Desmopressin. Ann Intern Med. 1985;103: 228-39.

237. Salzman EW, Weinstein MJ, Weintraub RM, Ware JA, Thurer RL, Robertson L, et al. Treatment with desmopressin acetate to reduce blood loss after cardiac surgery. A double-blind randomized trial. $N$ Engl J Med. 1986;314:1402-6.

238. Ansell J, Klassen V, Lew R, Ball S, Weinstein M, VanderSalm T, et al. Does desmopressin acetate prophylaxis reduce blood loss after valvular heart operations? A randomized, double-blind study. J Thorac Cardiovasc Surg. 1992;104: 117-23.

239. Rocha E, Llorens R, Páramo JA, Arcas R, Cuesta B, Trenor AM. Does desmopressin acetate reduce blood loss after surgery in patients on cardiopulmonary bypass? Circulation. 1988;77:1319-23.

240. Fremes SE, Wong BI, Lee E, Mai R, Christakis GT, McLean RF, et al. Metaanalysis of prophylactic drug treatment in the prevention of postoperative bleeding. Ann Thorac Surg. 1994;58:1580-8.

241. Levi M, Cromheecke ME, de Jonge E, Prins MH, de Mol BJ, Briët E, et al. Pharmacological strategies to decrease excessive blood loss in cardiac surgery: a meta-analysis of clinically relevant endpoints. Lancet. 1999;354: 1940-7.

242. Carless PA, Henry DA, Moxey AJ, O'Connell D, McClelland B, Henderson KM, et al. Desmopressin for minimising perioperative allogeneic blood transfusion. Cochrane Database Syst Rev. 2004;1:CD001884.

243. Mannucci PM. Hemostatic drugs. N Engl J Med. 1998;339:245-53.

244. Laupacis A, Fergusson D. Drugs to minimize perioperative blood loss in cardiac surgery: meta-analyses using perioperative blood transfusion as the outcome. The International Study of Peri-operative Transfusion (ISPOT) Investigators. Anesth Analg. 1997;85:1258-67.

245. Munoz JJ, Birkmeyer NJ, Birkmeyer JD, O'Connor GT, Dacey LJ. Is epsilonaminocaproic acid as effective as aprotinin in reducing bleeding with cardiac surgery?: a meta-analysis. Circulation. 1999;99:81-9.

246. Sedrakyan A, Treasure T, Elefteriades JA. Effect of aprotinin on clinical outcomes in coronary artery bypass graft surgery: a systematic review and metaanalysis of randomized clinical trials. J Thorac Cardiovasc Surg. 2004;128: 442-8.

247. Henry DA, Carless PA, Moxey AJ, O'Connell D, Stokes BJ, McClelland B, et al. Anti-fibrinolytic use for minimising perioperative allogeneic blood transfusion. Cochrane Database Syst Rev. 2007;4:CD001886. Update in: Cochrane Database Syst Rev. 2011;1:CD001886.

248. Mangano DT, Tudor IC, Dietzel C, Multicenter Study of Perioperative Ischemia Research Group; Ischemia Research and Education Foundation. The risk associated with aprotinin in cardiac surgery. $N$ Engl J Med. 2006;354: 353-65.

249. Shaw AD, Stafford-Smith M, White WD, Phillips-Bute B, Swaminathan M, Milano C, et al. The effect of aprotinin on outcome after coronary-artery bypass grafting. $N$ Engl J Med. 2008;358:784-93.

250. Schneeweiss S, Seeger JD, Landon J, Walker AM. Aprotinin during coronaryartery bypass grafting and risk of death. $N$ Engl J Med. 2008;358:771-83.

251. Hiatt WR. Observational studies of drug safety-aprotinin and the absence of transparency. N Engl J Med. 2006;355:2171-3.

252. Fergusson DA, Hébert PC, Mazer CD, Fremes S, MacAdams C, Murkin JM, et al. A comparison of aprotinin and lysine analogues in high-risk cardiac surgery. $N$ Engl J Med. 2008 May;358(22):2319-31. Erratum in: $N$ Engl J Med. 2010;363:1290

253. Murkin JM, Falter F, Granton J, Young B, Burt C, Chu M. High-dose tranexamic acid is associated with nonischemic clinical seizures in cardiac surgical patients. Anesth Analg. 2010;110:350-3

254. Levi M, Peters M, Buller HR. Efficacy and safety of recombinant factor VIIa for treatment of severe bleeding: a systematic review. Crit Care Med. 2005;33: 883-90.
255. Levi MM, Vink R, de Jonge E. Management of bleeding disorders by prohemostatic therapy. Int J Hematol. 2002;76(Suppl. 2):139-44.

256. von Heymann C, Redlich U, Jain U, Kastrup M, Schroeder T, Sander M, et al Recombinant activated factor VII for refractory bleeding after cardiac surgery-a retrospective analysis of safety and efficacy. Crit Care Med. 2005; 33:2241-6.

257. Dunkley S, Phillips L, McCall P, Brereton J, Lindeman R, Jankelowitz G, et al. Recombinant activated factor VII in cardiac surgery: experience from the Australian and New Zealand Haemostasis Registry. Ann Thorac Surg. 2008;85:836-44.

258. Diprose P, Herbertson MJ, O'Shaughnessy D, Gill RS. Activated recombinant factor VII after cardiopulmonary bypass reduces allogeneic transfusion in complex non-coronary cardiac surgery: randomized double-blind placebo-controlled pilot study. Br J Anaesth. 2005;95:596-602.

259. Gill R, Herbertson M, Vuylsteke A, Olsen PS, von Heymann C, Mythen M, et al Safety and efficacy of recombinant activated factor VII: a randomized placebocontrolled trial in the setting of bleeding after cardiac surgery. Circulation. 2009; $120: 21-7$

260. Hardy JF, Bélisle S, Van der Linden P. Efficacy and safety of activated recombinant factor VII in cardiac surgical patients. Curr Opin Anaesthesiol. 2009;22:95-9.

261. Karlsson M, Ternstrom L, Hyllner M, Baghaei F, Flinck A, Skrtic S, et al. Prophylactic fibrinogen infusion reduces bleeding after coronary artery bypass surgery. A prospective randomised pilot study. Thromb Haemost. 2009;102:137-44.

262. Levy JH, Gill R, Nussmeier NA, Olsen PS, Andersen HF, Booth FV, et al. Repletion of factor XIII following cardiopulmonary bypass using a recombinant A-subunit homodimer. A preliminary report. Thromb Haemost. 2009;102. 765-71.

263. Crémieux PY, Barrett B, Anderson K, Slavin MB. Cost of outpatient blood transfusion in cancer patients. J Clin Oncol. 2000;18:2755-61.

264. Cantor SB, Hudson DV Jr, Lichtiger B, Rubenstein EB. Costs of blood transfusion: a process-flow analysis. J Clin Oncol. 1998;16:2364-70.

265. The cost of blood: multidisciplinary consensus conference for a standard methodology. Transfus Med Rev. 2005;19:66-78.

266. Shander A, Hofmann A, Ozawa S, Theusinger OM, Gombotz H, Spahn DR. Activity-based costs of blood transfusions in surgical patients at four hospitals. Transfusion. 2010;50:753-65.

267. Shander A, Hofmann A, Gombotz H, Theusinger OM, Spahn DR. Estimating the cost of blood: past, present, and future directions. Best Pract Res Clin Anaesthesiol. 2007;21:271-89.

268. Hofmann A, Farmer S, Shander A. Cost-effectiveness in haemotherapies and transfusion medicine. ISBT Science Series. 2009;4(n2):258-65.

269. Saberton PJ, Paez A, Newbold KB, Heddle NM. Geographical variations in the correlates of blood donor turnout rates: an investigation of Canadian metropolitan areas. Int J Health Geogr. 2009;8:56.

270. Wells AW, Mounter PJ, Chapman CE, Stainsby D, Wallis JP. Where does blood go? Prospective observational study of red cell transfusion in north England. BMJ. 2002;325:803.

271. Thomson A, Farmer S, Hofmann A, Isbister J, Shander A. Patient blood management - a new paradigm for transfusion medicine? ISBT Science Series. 2009;4(n2):423-35.

272. Bernard AC, Davenport DL, Chang PK, Vaughan TB, Zwischenberger JB. Intraoperative transfusion of $1 \mathrm{U}$ to $2 \mathrm{U}$ packed red blood cells is associated with increased 30-day mortality, surgical-site infection, pneumonia, and sepsis in general surgery patients. J Am Coll Surg. 2009;208:931-7. 937.e1-2; discussion 938-9.

273. Taylor RW, Manganaro L, O'Brien J, Trottier SJ, Parkar N, Veremakis C. Impact of allogenic packed red blood cell transfusion on nosocomial infection rates in the critically ill patient. Crit Care Med. 2002;30:2249-54.

274. Taylor RW, O'Brien J, Trottier SJ, Manganaro L, Cytron M, Lesko MF, et al Red blood cell transfusions and nosocomial infections in critically ill patients. Crit Care Med. 2006;34:2302-8. quiz 2309.

275. Corwin HL, Gettinger A, Pearl RG, Fink MP, Levy MM, Abraham E, et al. The CRIT Study: Anemia and blood transfusion in the critically ill-current clinical practice in the United States. Crit Care Med. 2004;32:39-52.

276. Shander A. Emerging risks and outcomes of blood transfusion in surgery. Semin Hematol. 2004;41(1 Suppl. 1):117-24.

277. Scott BH, Seifert FC, Grimson R. Blood transfusion is associated with increased resource utilisation, morbidity and mortality in cardiac surgery. Ann Card Anaesth. 2008;11:15-9.

278. Banbury MK, Brizzio ME, Rajeswaran J, Lytle BW, Blackstone EH. Transfusion increases the risk of postoperative infection after cardiovascular surgery. $J$ Am Coll Surg. 2006;202:131-8. 
279. Glasziou P, Chalmers I, Rawlins M, McCulloch P. When are randomised trials unnecessary? Picking signal from noise. BMJ. 2007;334:349-51.

280. Helm RE, Rosengart TK, Gomez M, Klemperer JD, DeBois WJ, Velasco F, et al. Comprehensive multimodality blood conservation: 100 consecutive CABG operations without transfusion. Ann Thorac Surg. 1998;65: 125-36.

281. Moskowitz DM, Klein JJ, Shander A, Cousineau KM, Goldweit RS, Bodian C, et al. Predictors of transfusion requirements for cardiac surgical procedures at a blood conservation center. Ann Thorac Surg. 2004;77:626-34. Erratum in: Ann Thorac Surg. 2004;78:390.
282. Moskowitz DM, McCullough JN, Shander A, Klein JJ, Bodian CA, Goldweit RS, et al. The impact of blood conservation on outcomes in cardiac surgery: is it safe and effective? Ann Thorac Surg. 2010;90:451-8.

283. Ghiglione M. Blood management: a model of excellence. Clin Leadersh Manag Rev. 2007;21:E2.

284. Brevig J, McDonald J, Zelinka ES, Gallagher T, Jin R, Grunkemeier GL. Blood transfusion reduction in cardiac surgery: multidisciplinary approach at a community hospital. Ann Thorac Surg. 2009;87:532-9.

285. Green JA. Blood conservation in cardiac surgery: the Virginia Commonwealth University (VCU) experience. J Cardiothorac Vasc Anesth. 2004;18(4 Suppl):18S-23. 
Cardiopulmonary bypass

- Pump type

- Circuit type (closed vs open)

- Minimal cardiopulmonary bypass technology

- Impact of different kinds of coating

- Heparin management-reduction of systemic heparinization

- Hemodilution-impact on transfusions

- Techniques to reduce hemodilution (retro-prime, etc)

- Shed blood management-cell saving

- Ultrafiltration

"Cardiac Surgical Procedures"[MeSH] AND ("Blood Loss, Surgical”[MeSH] OR "Postoperative Hemorrhage"[MeSH] OR "Hemostasis" [MeSH] OR "Hemostatic Techniques" [MeSH] OR "Blood Component Transfusion" [MeSH]) AND ("Clinical Trial" [Publication Type] OR "Controlled Clinical Trial" [Publication Type] OR "Randomized Controlled Trial" [Publication Type] OR "Meta-Analysis" [Publication Type] OR "Guideline" [Publication Type] OR "Practice Guideline" [Publication Type] OR "Review" [Publication Type]) AND ("Cardiopulmonary Bypass”[MeSH] OR

"Cardiopulmonary Bypass/methods" [MeSH])

Preoperative and perioperative fluid and hemodilution management

- Preoperative fluid management

- Colloids vs crystalloids

- Postoperative fluid management

- Preoperative conditions-body surface area, body mass index, anemia, etc

- Strategies to increase the hemoglobin value

"Cardiac Surgical Procedures"[MeSH] AND ("Blood Loss, Surgical”[MeSH] OR "Postoperative Hemorrhage"[MeSH] OR "Hemostasis" [MeSH] OR "Hemostatic Techniques"[MeSH] OR "Blood Component Transfusion" [MeSH]) AND ("Clinical Trial” [Publication Type] OR "Controlled Clinical Trial” [Publication Type] OR "Randomized Controlled Trial" [Publication Type] OR "Meta-Analysis" [Publication Type] OR "Guideline" [Publication Type] OR "Practice Guideline" [Publication Type] OR "Review" [Publication Type]) AND ("Fluid Therapy" [MeSH] OR "Blood Volume" [MeSH] OR "Solutions" [MeSH] OR "Colloids" [MeSH] OR "Hetastarch" [MeSH] OR "crystalloid solutions" [Substance Name] OR "Hematocrit" [MeSH] OR "Erythrocyte Indices” [MeSH] OR “Anemia” [MeSH] OR "Serum Albumin" [MeSH] OR "Body Mass Index" [MeSH] OR "Cardiac Output, Low”[MeSH] OR "Blood Pressure”[ $[\mathrm{MeSH}]$ ) Physiologic signs of organ dysoxia during and after operation

- Mixed venous oxygen saturation and central venous oxygen saturation-acceptable range

- Serum lactates

- Factors affecting the alveolar-arterial oxygen difference-ventilation, cardiac output

- Markers of organ dysoxia—cardiac (troponin), renal, visceral organs

- New anticoagulants and heparin

- Influence of hematocrit on perioperative myocardial infarction, mesenteric ischemia

- Association between hemoglobin content and organ dysfunction

"Cardiac Surgical Procedures" [MeSH] AND ("Blood Loss, Surgical”[MeSH] OR "Postoperative Hemorrhage”[MeSH] OR "Hemostasis" [MeSH] OR "Hemostatic Techniques" [MeSH] OR "Blood Component Transfusion” [MeSH]) AND ("Clinical Trial" [Publication Type] OR "Controlled Clinical Trial” [Publication Type] OR "Randomized Controlled Trial" [Publication Type] OR "Meta-Analysis" [Publication Type] OR "Guideline" [Publication Type] OR "Practice Guideline" [Publication Type] OR "Review" [Publication Type]) AND ("Extracorporeal Circulation" [MeSH] OR Extracorporeal Membrane Oxygenation[MeSH] OR "Respiration, Artificial” [MeSH] OR "High-Frequency Ventilation” $[\mathrm{MeSH}] \mathrm{OR}$ “Liquid Ventilation” $[\mathrm{MeSH}] \mathrm{OR}$ “Positive-Pressure Respiration” $[\mathrm{MeSH}] \mathrm{OR}$ "Ventilator Weaning" $[\mathrm{MeSH}])$

"Cardiac Surgical Procedures"[MeSH] AND ("Clinical Trial” [Publication Type] OR "Controlled Clinical Trial" [Publication Type] OR "Randomized Controlled Trial" [Publication Type] OR "Meta-Analysis" [Publication Type] OR "Guideline" [Publication Type] OR "Practice Guideline" [Publication Type] OR "Review" [Publication Type]) AND (“Anoxia” [MeSH] OR "Blood Gas Analysis" [MeSH] OR "Oxygen Consumption"[MeSH]) AND ("Cardiac Output”[MeSH] OR "Stroke Volume” [MeSH])

"Cardiac Surgical Procedures"[MeSH] AND ("Clinical Trial” [Publication Type] OR "Controlled Clinical Trial" [Publication Type] OR "Randomized Controlled Trial" [Publication Type] OR "Meta-Analysis" [Publication Type] OR "Guideline" [Publication Type] OR "Practice Guideline" [Publication Type] OR "Review" [Publication Type]) AND (“Acid-Base Equilibrium”[MeSH] OR “Acid-Base Imbalance"[MeSH] OR “Acidosis”[MeSH]) 
Topic, subtopic, and MeSH terms

"Cardiac Surgical Procedures"[MeSH] AND ("Blood Loss, Surgical”[MeSH] OR "Postoperative Hemorrhage"[MeSH] OR "Hemostasis" [MeSH] OR "Hemostatic Techniques” [MeSH] OR "Blood Component Transfusion” [MeSH]) AND ("Clinical Trial" [Publication Type] OR "Controlled Clinical Trial" [Publication Type] OR "Randomized Controlled Trial" [Publication Type] OR "Meta-Analysis" [Publication Type] OR "Guideline" [Publication Type] OR "Practice Guideline" [Publication Type] OR "Review” [Publication Type]) AND (“Anoxia”[MeSH] OR "Cell Hypoxia”[MeSH] OR “Hypoxia, Brain”[MeSH])

"Cardiac Surgical Procedures"[MeSH] AND ("Clinical Trial” [Publication Type] OR "Controlled Clinical Trial” [Publication Type] OR "Randomized Controlled Trial" [Publication Type] OR "Meta-Analysis" [Publication Type] OR "Guideline" [Publication Type] OR "Practice Guideline" [Publication Type] OR "Review" [Publication Type]) AND ("Anoxia” [MeSH] OR "Blood Gas Analysis" [MeSH] OR "Oxygen Consumption" [MeSH]) AND ("Brain”[MeSH] OR "Brain/blood supply”[MeSH] OR "Brain/diagnosis"[MeSH] OR "Kidney”[MeSH] OR "Kidney/blood supply”[MeSH] OR “Kidney/diagnosis”[MeSH] OR “Heart”[MeSH] OR “Heart/diagnosis”[MeSH] OR "Troponin" $[\mathrm{MeSH}])$

"Cardiac Surgical Procedures"[MeSH] AND ("Clinical Trial" [Publication Type] OR "Controlled Clinical Trial" [Publication Type] OR "Randomized Controlled Trial" [Publication Type] OR "Meta-Analysis" [Publication Type] OR "Guideline" [Publication Type] OR "Practice Guideline" [Publication Type] OR "Review" [Publication Type]) AND (“Anoxia”[MeSH] OR “Cell Hypoxia”[MeSH] OR "Hypoxia, Brain”[MeSH])

Clinical assessment, decision, and judgment

- Impact of invasive procedures before the operation

- Strategies to optimize the coagulation profile before the operation

- Role of anti-platelet drugs-time for withdrawal

- Blood loss assessment (timing and amount)

- Reoperation (timing and impact on transfusion)

“Cardiac Surgical Procedures”[MeSH] AND ("Blood Loss, Surgical”[MeSH] OR "Postoperative Hemorrhage”[MeSH] OR "Hemostasis" [MeSH] OR "Hemostatic Techniques" [MeSH] OR "Blood Component Transfusion" [MeSH]) AND ("Clinical Trial" [Publication Type] OR "Controlled Clinical Trial" [Publication Type] OR "Randomized Controlled Trial" [Publication Type] OR "Meta-Analysis" [Publication Type] OR "Guideline" [Publication Type] OR "Practice Guideline" [Publication Type] OR "Review" [Publication Type]) AND ("Heart Catheterization" [MeSH] OR “Angioplasty, Transluminal, Percutaneous Coronary" [MeSH] OR "Catheter Ablation” [MeSH] OR "Preoperative Care" $[\mathrm{MeSH}])$

“Cardiac Surgical Procedures"[MeSH] AND ("Blood Loss, Surgical”[MeSH] OR "Postoperative Hemorrhage”[MeSH] OR "Hemostasis" [MeSH] OR "Hemostatic Techniques” [MeSH] OR "Blood Component Transfusion”[MeSH]) AND ("Clinical Trial" [Publication Type] OR "Controlled Clinical Trial" [Publication Type] OR "Randomized Controlled Trial" [Publication Type] OR "Meta-Analysis" [Publication Type] OR "Guideline" [Publication Type] OR "Practice Guideline" [Publication Type] OR "Review" [Publication Type]) AND ("Platelet Aggregation Inhibitors" [MeSH] OR "Hemorrhage/chemically induced"[MeSH]) AND "Time Factors"[MeSH]

“Cardiac Surgical Procedures”[MeSH] AND ("Blood Loss, Surgical”[MeSH] OR "Postoperative Hemorrhage”[MeSH] OR "Hemostasis" [MeSH] OR "Hemostatic Techniques"[MeSH] OR "Blood Component Transfusion" [MeSH]) AND ("Clinical Trial" [Publication Type] OR "Controlled Clinical Trial" [Publication Type] OR "Randomized Controlled Trial" [Publication Type] OR "Meta-Analysis" [Publication Type] OR "Guideline" [Publication Type] OR "Practice Guideline" [Publication Type] OR "Review" [Publication Type]) AND “Blood Loss, Surgical”[MeSH] AND "Time Factors" $[\mathrm{MeSH}]$

"Cardiac Surgical Procedures"[MeSH] AND ("Blood Loss, Surgical" [MeSH] OR "Postoperative Hemorrhage"[MeSH] OR "Hemostasis" [MeSH] OR "Hemostatic Techniques"[MeSH] OR "Blood Component Transfusion" [MeSH]) AND ("Clinical Trial" [Publication Type] OR "Controlled Clinical Trial" [Publication Type] OR "Randomized Controlled Trial" [Publication Type] OR "Meta-Analysis" [Publication Type] OR "Guideline" [Publication Type] OR "Practice Guideline" [Publication Type] OR "Review" [Publication Type]) AND "Reoperation”[MeSH] AND "Time Factors" $[\mathrm{MeSH}]$

“Cardiac Surgical Procedures"[MeSH] AND ("Blood Loss, Surgical”[MeSH] OR "Postoperative Hemorrhage"[MeSH] OR "Hemostasis" [MeSH] OR "Hemostatic Techniques”[MeSH] OR "Blood Component Transfusion”[MeSH]) AND ("Clinical Trial" [Publication Type] OR "Controlled Clinical Trial" [Publication Type] OR "Randomized Controlled Trial" [Publication Type] OR "Meta-Analysis" [Publication Type] OR "Guideline" [Publication Type] OR "Practice Guideline" [Publication Type] OR "Review" [Publication Type]) AND ("Heart Catheterization" $[\mathrm{MeSH}] \mathrm{OR}$ "Angioplasty, Transluminal, Percutaneous Coronary" [MeSH] OR "Catheter Ablation" [MeSH] OR "Preoperative Care" $[\mathrm{MeSH}])$

\begin{tabular}{cc} 
Date* $^{*}$ & No. of hits \\
\hline April 29 & 5
\end{tabular}

April 29

55

July 2

April 9 
Blood management policy

- Nonmedical strategies to reduce blood product use

- Health economic analyses that includes both cost of transfusion metrics and cost of nontransfusion

- Overtransfusion rather than nontransfusion

- All cost-effectiveness assessments on safety rather than intended effectiveness

"Cardiac Surgical Procedures"[MAJR] AND ("Blood Loss, Surgical”[MAJR] OR "Postoperative Hemorrhage" [MAJR]

OR "Hemostasis"[MAJR] OR "Hemostatic Techniques"[MAJR] OR "Blood Component Transfusion"[MAJR]) AND ("Health Policy” [MeSH] OR "Health Care Quality, Access, and Evaluation" [ MeSH] OR "Outcome Assessment (Health Care)"[ MeSH] OR "Delivery of Health Care"[ MeSH] OR "Health Services Research"[ MeSH] OR "Economics" [ MeSH] OR "Costs and Cost Analysis" [ MeSH] OR "Economic Competition" [ MeSH] OR "Economics, Hospital”[ MeSH] OR “Economics, Medical”[ MeSH] OR “Economics, Pharmaceutical”[ MeSH])

Blood product administration

- Time relationship between blood product administration and adverse events

- Adverse events with respect to the amount of PRBCs received

- Adverse events with respect to the storage time of the PRBCs received

- Adverse events with respect to each allogeneic blood product (PRBCs, fresh-frozen plasma, platelets)

"Cardiac Surgical Procedures"[MeSH] AND ("Clinical Trial” [Publication Type] OR "Controlled Clinical Trial" [Publication Type] OR "Randomized Controlled Trial” [Publication Type] OR "Meta-Analysis" [Publication Type] OR "Guideline" [Publication Type] OR "Practice Guideline" [Publication Type] OR "Review" [Publication Type]) AND (("Blood Component Transfusion" [MeSH] OR "Erythrocyte Transfusion" [MeSH] OR "Platelet Transfusion" [MeSH] OR "Plasma" $[\mathrm{MeSH}]$ ) AND ("Outcome Assessment (Health Care)"[MeSH] OR "Time Factors"[MeSH]) OR ("Leukocyte Reduction Procedures"[MeSH] OR "Blood Donors"[MeSH]))

"Cardiac Surgical Procedures"[MeSH] AND (("Blood Component Transfusion”[MeSH] OR "Erythrocyte Transfusion”[MeSH] OR "Platelet Transfusion”[MeSH] OR "Plasma”[MeSH]) AND ("Outcome Assessment (Health Care)" [MeSH] OR “Time Factors “[MeSH]) OR ("Leukocyte Reduction Procedures”[ $[\mathrm{MeSH}] \mathrm{OR}$ "Blood Donors” [MeSH]))

Adverse outcomes

- Definition of the major complications (myocardial infarction, atrial fibrillation, stroke, acute renal failure, infections)

- Relationship between transfusions and adverse outcomes

"Cardiac Surgical Procedures"[MeSH] AND "Erythrocyte Transfusion”[MeSH]

"Cardiac Surgical Procedures" [MeSH] AND ("Clinical Trial” [Publication Type] OR "Controlled Clinical Trial" [Publication Type] OR "Randomized Controlled Trial" [Publication Type] OR "Meta-Analysis" [Publication Type] OR "Guideline" [Publication Type] OR "Practice Guideline" [Publication Type] OR "Review" [Publication Type]) AND "Erythrocyte Transfusion” [MeSH]

Pharmacologic strategies to reduce bleeding

- Type and dose of drugs used before and during the operation

- Type and dose of drugs used after the operation

"Cardiac Surgical Procedures”[MeSH] AND (“Blood Loss, Surgical”[MeSH] OR "Postoperative Hemorrhage”[MeSH] OR "Hemostasis" [MeSH] OR "Hemostatic Techniques" [MeSH] OR "Blood Component Transfusion”[MeSH]) AND ("Clinical Trial” [Publication Type] OR "Controlled Clinical Trial” [Publication Type] OR "Randomized Controlled Trial” [Publication Type] OR "Meta-Analysis" [Publication Type] OR "Guideline" [Publication Type] OR "Practice Guideline" [Publication Type] OR "Review" [Publication Type]) AND ("Hematologic Agents"[MeSH] OR

“Coagulants”[MeSH] OR "Hemostatics" [MeSH] OR "Antifibrinolytic Agents"[MeSH] OR "Heparin Antagonists" [MeSH] OR “Blood Coagulation Factors"[MeSH] OR "Fibrin”[MeSH] OR "Factor VII"[MeSH] OR “Factor XIII”[MeSH] OR “Thrombin”[MeSH] OR “Fibrin Foam”[MeSH] OR "Fibrin Tissue Adhesive”[MeSH] OR "Deamino Arginine Vasopressin" [MeSH])

Laboratory and point-of-care tests

- Routine laboratory (international normalized ratio, activated partial thromboplastin time) assays during and after operation

- Role of thromboelastography, platelet function tests in guiding the transfusion policy

- Advantages of heparin and protamine monitoring system

"Cardiac Surgical Procedures" [MeSH] AND ("Blood Loss, Surgical" [MeSH] OR "Postoperative Hemorrhage" [MeSH] OR "Hemostasis" [MeSH] OR "Hemostatic Techniques" [MeSH] OR "Blood Component Transfusion" [MeSH]) AND ("Clinical Trial" [Publication Type] OR "Controlled Clinical Trial" [Publication Type] OR "Randomized Controlled Trial" [Publication Type] OR "Meta-Analysis" [Publication Type] OR "Guideline" [Publication Type] OR "Practice Guideline" [Publication Type] OR "Review" [Publication Type]) AND ("Point-of-Care Systems"[MeSH] OR "Hematologic Tests"[MeSH] OR "Laboratory Techniques and Procedures" [MeSH] OR "Platelet Count”[MeSH]) 
High-risk subpopulations

- Mechanical assistance

- Explants

- Emergencies (acute aortic dissection, heart rupture, etc)

- Hypothermic cardiac arrest

- Adult congenital heart disease patients-cyanotic patients

"Cardiac Surgical Procedures"[MeSH] AND ("Blood Loss, Surgical"[MeSH] OR "Postoperative Hemorrhage"[MeSH] OR "Hemostasis" [MeSH] OR "Hemostatic Techniques" [MeSH] OR "Blood Component Transfusion”[MeSH]) AND ("Clinical Trial" [Publication Type] OR "Controlled Clinical Trial" [Publication Type] OR "Randomized Controlled Trial" [Publication Type] OR "Meta-Analysis" [Publication Type] OR "Guideline" [Publication Type] OR "Practice Guideline" [Publication Type] OR "Review" [Publication Type]) AND ("Artificial Organs" [MeSH] OR "Heart, Artificial” $[\mathrm{MeSH}] \mathrm{OR}$ "Heart-Assist Devices" [MeSH] OR "Heart-Lung Machine"[MeSH] OR "Pacemaker, Artificial" $[\mathrm{MeSH}])$

"Cardiac Surgical Procedures"[MeSH] AND ("Blood Loss, Surgical”[MeSH] OR "Postoperative Hemorrhage”[MeSH] OR "Hemostasis" [MeSH] OR "Hemostatic Techniques" [MeSH] OR "Blood Component Transfusion" [MeSH]) AND ("Clinical Trial" [Publication Type] OR "Controlled Clinical Trial" [Publication Type] OR "Randomized Controlled Trial" [Publication Type] OR "Meta-Analysis" [Publication Type] OR "Guideline" [Publication Type] OR "Practice Guideline" [Publication Type] OR "Review" [Publication Type]) AND ("Emergencies"[MeSH] OR "Heart Rupture" $[\mathrm{MeSH}]$ OR "Aortic Rupture" $[\mathrm{MeSH}])$

"Cardiac Surgical Procedures" [MeSH] AND ("Blood Loss, Surgical” [MeSH] OR "Postoperative Hemorrhage"[MeSH] OR "Hemostasis" [MeSH] OR "Hemostatic Techniques”[MeSH] OR "Blood Component Transfusion” [MeSH]) AND ("Clinical Trial" [Publication Type] OR "Controlled Clinical Trial" [Publication Type] OR "Randomized Controlled Trial" [Publication Type] OR "Meta-Analysis" [Publication Type] OR "Guideline" [Publication Type] OR "Practice Guideline" [Publication Type] OR "Review" [Publication Type]) AND ("Heart Defects, Congenital”[MeSH] OR "Cardiac Output, Low" $[\mathrm{MeSH}])$

General limits included were English language, humans, all adults 19+ years, January 1994-April 2009. MeSH, Medical Subject Heading; PRBCs, packed red blood cells. *All searches were conducted during 2009. 